\title{
Minimization of Ground Vibration Test Configurations for F-16 Aircraft by Subtractive Modification
}

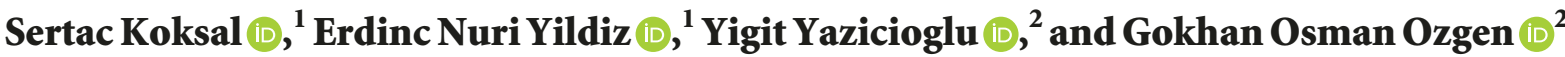 \\ ${ }^{1}$ Ekinoks-AG Defence Industry Corporation, Gazi Universitesi, \\ Golbasi Yerleskesi Teknoplaza Binasi C Blok Zemin Kat CZ15-16 06831, Ankara, Turkey \\ ${ }^{2}$ Middle East Technical University, Department of Mechanical Engineering Universiteler Mah, Dumlupinar Blv, No: 1, \\ 06800 Ankara, Turkey \\ Correspondence should be addressed to Sertac Koksal; skoksal@ekinoks-ag.com.tr
}

Received 18 August 2019; Accepted 8 October 2019; Published 7 November 2019

Academic Editor: Franck Poisson

Copyright ( 2019 Sertac Koksal et al. This is an open access article distributed under the Creative Commons Attribution License, which permits unrestricted use, distribution, and reproduction in any medium, provided the original work is properly cited.

\begin{abstract}
The certification process of external loads designed for aircraft needs to satisfy various criteria where compatibility with existing systems is one of the essential requirements. Flight flutter testing is a critical part of a certification process that requires many preliminary studies. Computational flutter analysis must precede actual flutter test to determine an approximately safe flight envelope to ensure the safety of the personnel and aircraft. To be able to perform flutter analysis of an aircraft, an accurate structural model such as finite element (FE) model is required. An accurate FE model can be obtained from a coarse model using ground vibration test (GVT) which is also the primary test campaign for certification of a new external load, new aircraft design, or modification on existing aircraft. On the other hand, performing GVT for each configuration of an aircraft is both time consuming and costly. It would be more practical to determine the critical configurations for an aircraft using computational tools and perform actual GVT for those configurations. The objective of this study is to simulate GVT characteristics for downloading and fuel configurations of F-16 aircraft. A novel methodology is proposed where various loading configurations can be simulated by subtractive modification from loaded GVT data so that joint stiffnesses between stores and aircraft need not be identified. The proposed technique decreases the number of necessary physical GVT testing campaigns.
\end{abstract}

\section{Introduction}

When designing an external store or ammunition for an existing fighter aircraft, the aircraft with the new store or ammunition should satisfy certification regulations of airworthiness authorities such as Federal Aviation Regulations (FAR), European Aviation Safety Agency (EASA), Joint Aviation Regulations (JAR), and Military (MIL). Flutter performance and determination of safe flight envelope are the main concerns in these certification procedures. Flutter characteristics of an aircraft can be estimated using mathematical models and simulations which may be validated by flight testing when needed. In order to perform flutter analysis, either a validated finite element (FE) model or the modal parameters of the aircraft should be available. Flutter analysis is performed to identify the aeroelastic behavior of aircraft during various flight conditions and determine the flight speed when flutter occurs. This analysis requires coupling of air flow and structural dynamics response of the aircraft. Ground vibration testing (GVT) is an industryaccepted experimental methodology to identify elastic modal frequencies, modal damping ratios, mode shape vectors, and modal mass data of an aircraft, which are directly or indirectly used in flutter analysis of the same aircraft. GVT-related issues such as the decision on the number of sensors for attaining optimum spatial resolution for the motion of major structural elements and prevention of spatial aliasing, mounting style of accelerometers $[1,2]$, methods for exciting the structure using electrodynamic shakers [3], and providing the free-free boundary conditions using soft suspension systems are well studied and documented in the literature.

Modal parameters obtained from GVT are directly usable for flutter analysis of small-size aircraft. For fighters or 
large transport aircraft, a finite element (FE) model will have to be used in the flutter analysis, which would require the model to be validated using GVT results (i.e., modal data identified from GVT). For fighter aircraft, there are numerous possible loading configurations if one considers different ammunitions, external stores, and fuel conditions. If flutter analysis is required to be performed for all of these configurations, a GVT will have to be performed for each configuration either to obtain the modal parameters to be used in the analysis or to validate the FE model to be used in the analysis. As an example, in the study by Morton, typical downloading permutations of an F-16 military fighter aircraft are calculated as 25000 . Through CFD analysis, a total of 75 configurations were identified as critical for which flight tests will have to be performed [4].

Performing large number of GVT is not practical, so a simulation-based methodology to decide on the flutter critical configurations would be quite useful when designing ammunition or external stores for fighter aircraft since this would reduce the number of actual GVT to be performed. Flutter critical downloading (underwing ammunition and external store) configurations can be mainly selected by the results of preliminary flutter analyses. GVT data can be simulated by using previous physical GVT results of different downloading configurations or a validated base FE model to perform preliminary flutter analyses for as many configurations as desired. If the results of preliminary flutter analyses seem critical, then these downloading configurations can be added to the actual test sequence when planning the physical GVT campaign. Later, the actual GVT test results can be utilized when performing the final flutter analysis for the configurations deemed critical by the preliminary analysis. When the literature is investigated, it is seen that such a methodology is not proposed or studied. On the other hand, there are studies where detailed FE models of the fighter aircraft for several downloading configurations are used to perform various flight stability-related analyses [5-9].

In this article, the simulation of GVT characteristics for downloading and fuel configurations of F-16 aircraft is studied. FE method can be used for the construction and assessment of a model that can simulate GVT, without having to use a physical aircraft. Typically, a detailed FE model is only available to the designer of an aircraft, and when an entity other than the designer needs to develop external components to be used with the aircraft, a coarse FE model is required in the least. For this study, a rough FE model of F-16 aircraft was built, updated, and correlated to GVT data for planning purposes as published in a previous study by the authors [10]. The rough model is constructed using 3D solid models and technical data available in the open literature. These solid models are mainly used for avocation purposes which are scaled down in a predetermined ratio. Structural elements and available structural models of F-16 are examined in detail from GVT perspective. An enhanced FE model of F-16 is obtained together with fuel, adapters, and external loads. The enhanced FE model is modified according to the configuration based on a reference [11] in the literature and verified with real GVT data given in the same reference. The modal data of the enhanced FE model is then used for simulations to plan a draft test matrix for the determination of the critical configurations to minimize the total number of tests in the GVT campaign. Sample downloading and fuel cases are also considered to demonstrate the change in the dynamic response of the F-16 aircraft together with the comparison of simulated modal data with physical GVT data obtained from experiments.

The methodology proposed in this study is based on obtaining predicted GVT data for various downloading configurations using previous physical GVT results of different downloading configurations or a validated FE model that can reproduce GVT data for various configurations by simply subtracting ammunitions from aircraft stations from a reference physical GVT result or a reference loaded FE model. Since munitions are much stiffer than the aircraft structure, their removal from the model can be done in the form of translational and rotational mass subtraction from the relevant locations of the mass matrix of the reference model. No modifications or identifications are required on the stiffness matrix when mass elements are removed since one side of the elastic element connecting the munition to the aircraft will be simply free. This approach is considerably easier than simulating the addition of munitions to an unloaded reference since the stiffness of the joints between aircraft, and the munitions would have to be known or identified. The same approach can be utilized for investigating the effect of fuel, starting from fully loaded configuration, and obtaining other fuel levels by simply subtracting fuel mass from reference. Overall, this methodology is a novel approach considering the relevant works in the literature where no similar methodology is used or presented.

The flowchart of the methodology that is presented and demonstrated on an F-16 aircraft in this paper is given in Figure 1 in order to clarify the details of the proposed methodology. Three different modal model definitions are used in the context of this study. Firstly, GVT simulations will be performed by using a validated base modal model that is named as initial model. Initial model is the one, on which the modifications will be performed since it is validated using the GVT data of the fully loaded aircraft. Initial model could be considered either as the experimental model that consists of actual GVT data or as the FE model updated and validated with the actual GVT data. Initial model should be constructed for an already existing configuration which is as similar as possible to the configurations for which simulations and flutter analyses are required. Secondly, simulated model is the modal model that is synthesized by subtracting and adding ammunitions and fuel from and to the initial model, respectively, when defined as actual GVT data or the updated and validated FE model. The simulated model is synthesized after the selected modification from a draft test matrix (in which all possible configurations for which flutter performance is planned to be checked are included) is performed by applying the proposed approach on the initial model. The method aims at generating a satisfactorily accurate simulated model for the designers (i.e., a modal model or an FE model that can accurately 


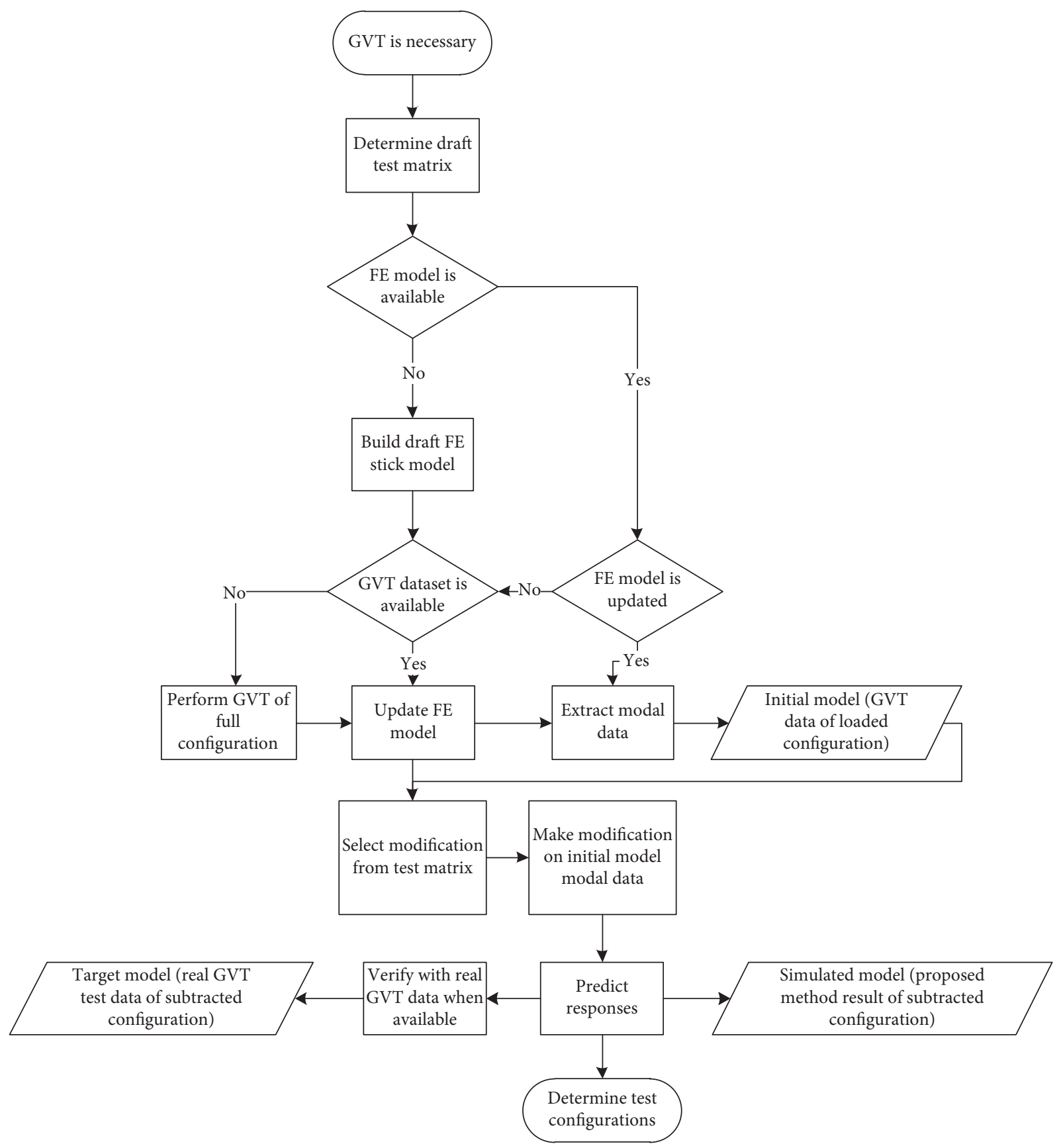

FIGURE 1: Flowchart and model definitions.

produce modal data from a simulated GVT test). In this study, the level of accuracy of the simulated model is validated by comparing it with the target model which contains the real modal data obtained from actual GVT of the same configuration. Target model may also be calculated from an updated and validated FE model when the modal data obtained from actual GVT are not directly available.

The work conducted on the development and demonstration of the proposed GVT simulation methodology starts with a description of how the equivalent FE model of F-16 is constructed. In Section 3, details of model updating work conducted for the constructed FE model of F-16 are given. The model is updated using the modal data obtained from GVT by using Bayesian parameter estimation method. The equivalent FE model is also validated with another configuration available in the literature [11]. In Section 4, GVT simulations for a draft test matrix are performed to show the effect of downloading on the dynamics of F-16 for different loading stations by using the proposed modification approach based on munition subtraction from the loaded configuration. Effect of fuel is analyzed in Section 5 . Analysis results presented in Section 4 and Section 5 are all validated by actual GVT results (i.e., modal data) to demonstrate the validity of the proposed methodology. 


\section{Construction of the Equivalent FE Model for F-16}

Structural dynamic response characteristics of F-16 are mainly determined by its structural elements together with its mass distribution. Forward, center, and aft fuselage sections, rightand left-wing boxes, and horizontal and vertical stabilizers are classified as the main structural components of an F-16 aircraft. When attached, pylons, munitions, adapters, stores, pods, and fuel tanks are some of the external loads that change the structural dynamic response characteristics of an F-16. The wing boxes that are the combination of ribs and spars are structurally significant components of F-16. There are ten and four different spar and rib positions in the wing box, respectively. Visual information on geometrical data and FE model for a wing can be found in $[12,13]$ Fuselage assembly composes of metal bulkheads, longerons, and sheet metal skins. Major bulkheads separate the sections, and they are machined components to be able to carry concentrated loads and satisfy functional requirements. Bending stability of F-16 is managed by longerons and longitudinal beams. Horizontal and vertical stabilizers can be named as the structural stabilizer group. Horizontal stabilizer has a metal frame and carbon fiber composite assemblies. Similar to the wing box, vertical stabilizer is built from ribs and spars. The external loads are also studied [14].

Denegri has given the grid point coordinates for the structural model of the wing of an F-16 [5]. Farhat et al. built a model for a missile and launching system at each wing tip based on modeling information from Lockheed Martin for F-16 Block 40 [6]. In another study, FE analysis results correctly estimate the first dry bending and torsion frequencies for measured data from GVT as 4.76 and $7.43 \mathrm{~Hz}$, respectively [7]. Lockheed Martin also uses a detailed FE model and simplified structural FE model $[8,9]$. First, four elastic modes of F-16 are found as symmetric wing bending mode, antisymmetric wing bending mode, symmetric wing torsion mode, and antisymmetric wing torsion mode.

The equivalent FE model of F-16, which will be used in this study, is constructed using technical data and solid model information available in the open literature. The constructed FE model is presented in Figure 2. In the model, there are 240 nodes, 452 beam elements with 119 properties, 23 multipoint constraints (MPCs), and 1 material (aluminum) property.

The natural frequencies obtained using the equivalent FE model in free-free boundary conditions are given in Table 1. The first two mode shapes are also given in Figure 3 . It is clear that the initial version of the equivalent FE model cannot produce accurate enough results; thus, it is not suitable to use in GVT simulations. The equivalent FE model will have to be updated together with the external loads.

\section{Updating and Validation of F-16 Equivalent FE Model}

F-16 aircraft has 11 hard points (stations) where the external loads can be attached. The station numbers are depicted in Figure 4. The configuration to be used in this study for updating is given as in Table 2.

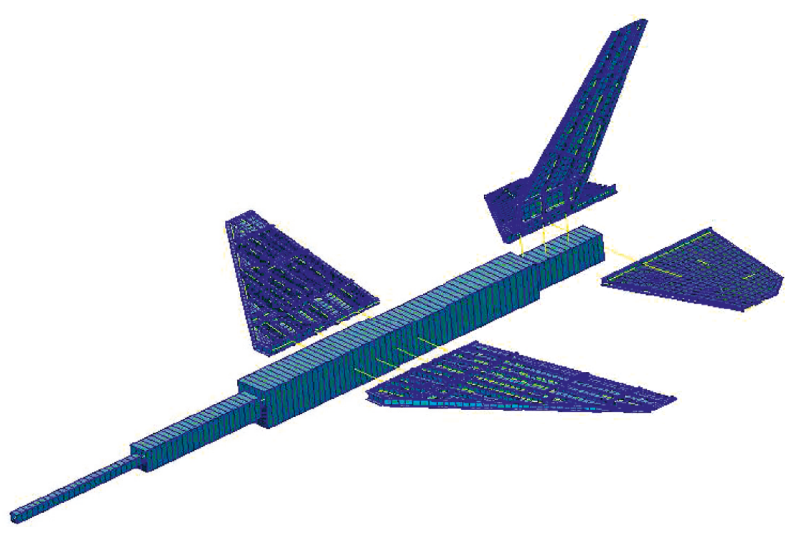

FIGURE 2: Equivalent FE model of F-16.

TABLE 1: Modal parameters calculated using the equivalent FE model.

\begin{tabular}{lc}
\hline Mode number & Frequency $(\mathrm{Hz})$ \\
\hline 1 & 4.85 \\
2 & 4.95 \\
3 & 5.23 \\
4 & 5.79 \\
5 & 7.01 \\
6 & 12.18 \\
7 & 15.33 \\
8 & 15.39 \\
9 & 15.40 \\
10 & 15.65 \\
11 & 16.91 \\
12 & 17.46 \\
13 & 24.21 \\
14 & 24.33 \\
\hline
\end{tabular}

Bayesian parameter estimation method of FEMtools ${ }^{\circledR}$ software is used for model updating. Bayesian parameter estimation method is a sensitivity-based method where an error term defined in terms of calculated sensitivities of updating parameters to modal parameters is sought to be minimized [15]. The assumed measurement points that are used for updating is shown in Figure 5.

Design parameters are taken as cross section of beam elements, Young's modulus, shear modulus, plate or shell thickness, beam moment of inertia, mass moment of inertia, spring stiffness, and Poisson value. Resonance frequencies, structural mass properties, and modal assurance criteria (MAC) values, a measure of how two mode shapes are spatially correlated, are used as design constraints. Minimization of the error by Bayesian parameter estimation method is the design objective. Displacements of the test model and FE model are correlated with maximum MAC threshold. The correlation of draft FE model and GVT data is given in Table 3. Modal assurance criteria (MAC) matrix before the updating process is given in Figure 6. The model on which updating is conducted is given in Figure 7. Mass distribution is the other factor for the updating process. The mass distribution of aircraft is taken as given in Table 4.

In the updating process, it is determined that the convergence criteria of the wing can be met by using shell elements as observed in similar models in the literature. The correlation data and MAC matrix after the model updating 


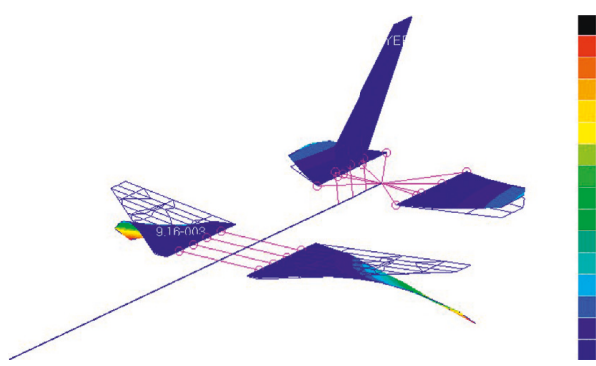

(a)

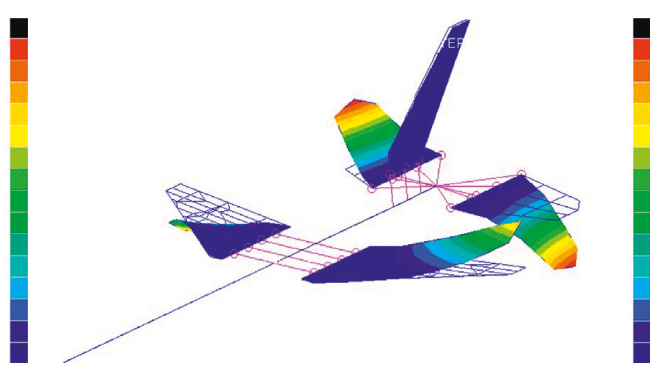

(b)

FIGURE 3: First two elastic mode shapes obtained using the equivalent FE model: (a) first elastic mode and (b) second elastic mode.

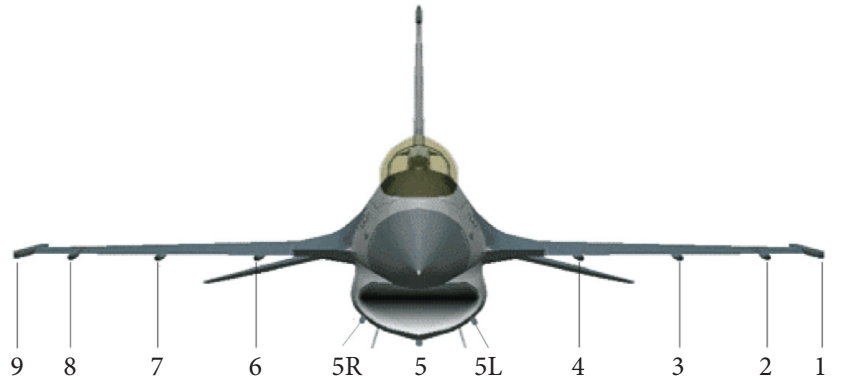

FIgURE 4: F-16 hard points.

TABLE 2: Configurations for model updating.

\begin{tabular}{|c|c|}
\hline Station & Load \\
\hline 1 & LAU-129 + AIM-120 (AA1) \\
\hline 2 & $16 \mathrm{~S} 301+16 \mathrm{~S} 210+\mathrm{AIM}-9(\mathrm{AA} 2)$ \\
\hline 3 & $16 S 1700+$ GBU31 JDAM (GBU31) \\
\hline 4 & 370 gal empty fuel tank plus pylon (Tank-1) \\
\hline $5 \mathrm{~L}$ & AAQ-13 (P-1) \\
\hline 5 & 300 gal empty fuel tank plus pylon (Tank-2) \\
\hline $5 \mathrm{R}$ & AAQ-14 (P-2) \\
\hline 6 & 370 gal empty fuel tank plus pylon (Tank-1) \\
\hline 7 & $16 S 1700+$ GBU31 JDAM (GBU31) \\
\hline 8 & $16 \mathrm{~S} 301+16 \mathrm{~S} 210+\mathrm{AIM}-9(\mathrm{AA} 2)$ \\
\hline 9 & LAU-129 + AIM-120 (AA1) \\
\hline
\end{tabular}

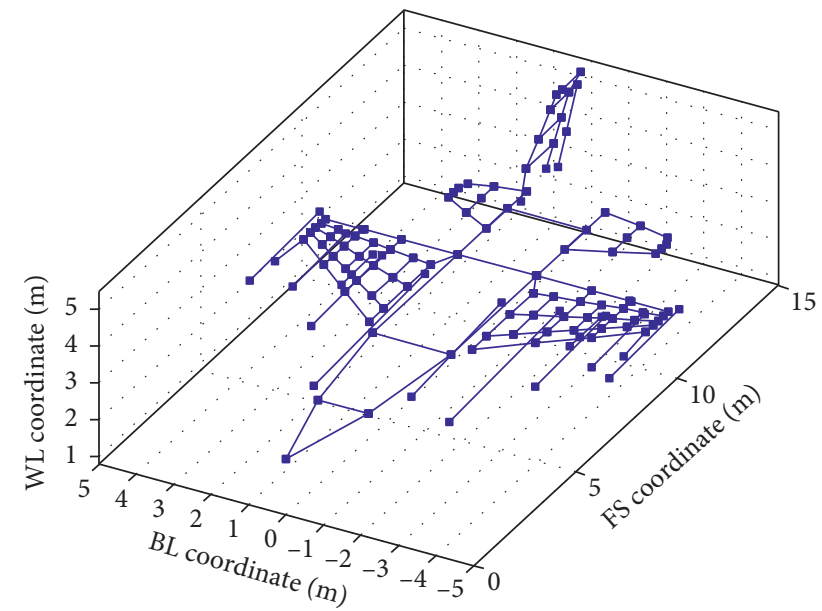

FIgURE 5: F-16 measurement points for FE model updating purposes. process are shown in Table 5 and Figure 8, respectively. Thicknesses of shell elements and elasticity modulus are checked for physical feasibility.

The updating is performed for the first ten elastic modes which are assumed to be enough for flutter analysis. The mode shapes of the updated FE model and the mode shapes identified from GVT are shown in the same figures (Figure 9) in order to prove that the updated FE model is dynamically accurate. The updated FE model of F-16 is verified concerning the other available results given in the literature. One of the contributions for F-16 GVT is given recently by Nöel et al. [11]. In that study, GVT is performed on a full-scale F-16 aircraft in September 2012 at the Saffraanberg military base in Belgium. F-16 was loaded with two AIM-9 munitions at wing tips and an Mk-82 store at the pylon of the left wing. Updated FE model is loaded with two AIM-9 munitions at wing tips and an Mk-82 store at the pylon of the left wing as same as the downloading configuration in [11]. The results of the verification of the updated FE model are shown in Figure 10. Model frequency results of the verified model are given in Table 6.

\section{Method}

In this study, GVT data of an updated model or a previous test campaign are used to predict the structural dynamic response of the F-16 aircraft. The modification is performed by using GVT data and physical properties of the new design. The frequency range of interest is assumed from the necessities of flutter requirements. External load modifications on F-16 are considered as mass modifications. The formulation for mass modification can be given as follows:

$$
[M]\{\ddot{x}\}+[K]\{x\}=\{0\},
$$

where $[M]$ is the mass matrix, $[K]$ is the stiffness matrix, and the $\{x\}$ is the degrees of freedom vector.

For $\{x(t)\}=\{\bar{X}\} e^{i \omega t}$

$$
\left([K]-\omega^{2}[M]\right)\{\bar{X}\}=\{0\},
$$

where $\omega$ is the frequency.

For $\{\bar{X}\}=[\varphi]\{\eta\}$,

$$
\begin{aligned}
{[\varphi]^{T}[K][\varphi] } & =\left[D_{\mathrm{e}}\right], \\
{[\varphi]^{T}[M][\varphi] } & =[I],
\end{aligned}
$$


TABLE 3: Correlation data before model updating.

\begin{tabular}{lcccc}
\hline FEA mode & FEA frequency $(\mathrm{Hz})$ & GVT mode & Absolute difference $(\%)$ & MAC $(\%)$ \\
\hline 1 & 3.30 & 1 & 24.76 & 76.6 \\
2 & 6.93 & 4 & 39.34 & 89.6 \\
3 & 7.46 & 3 & 30.27 & 68.3 \\
4 & 8.20 & 15 & 12.41 & 71.7 \\
5 & 8.34 & 9 & 15.07 & 74.9 \\
6 & 8.40 & 10 & 5.67 & 16.1 \\
7 & 10.33 & 12 & 0.46 & 47.4 \\
8 & 11.00 & 13 & 12.59 & 42.7 \\
9 & 11.07 & 17 & 28.6 & 20.1 \\
10 & 11.42 & 8 & 12.84 & 24.9 \\
11 & 13.17 & 14 & & \\
\hline
\end{tabular}

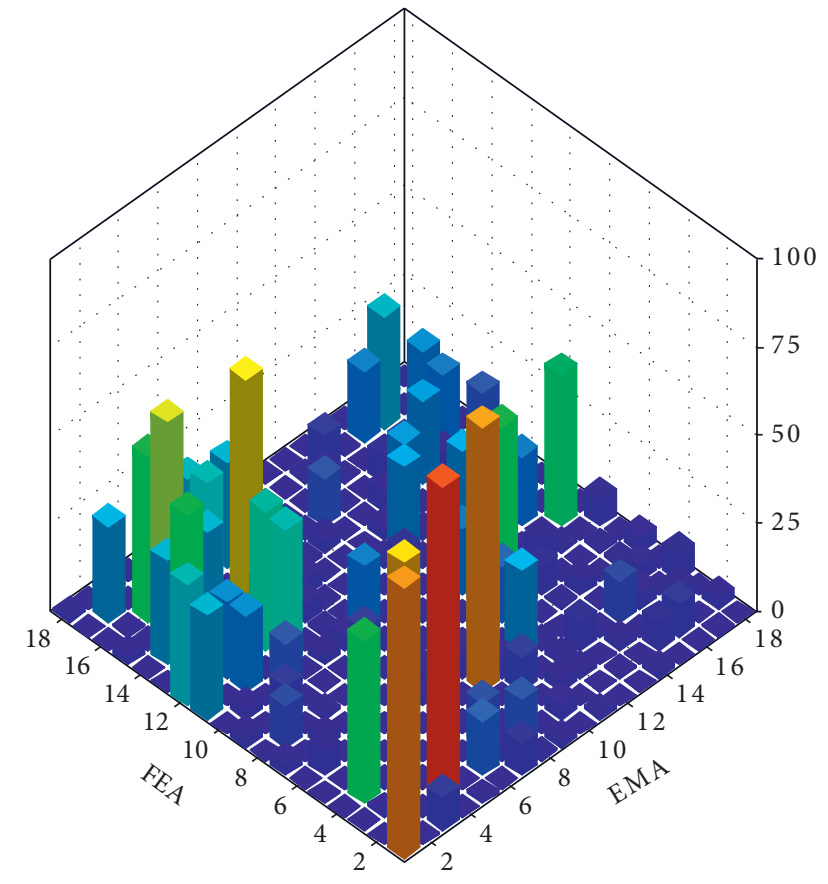

Figure 6: MAC before updating.

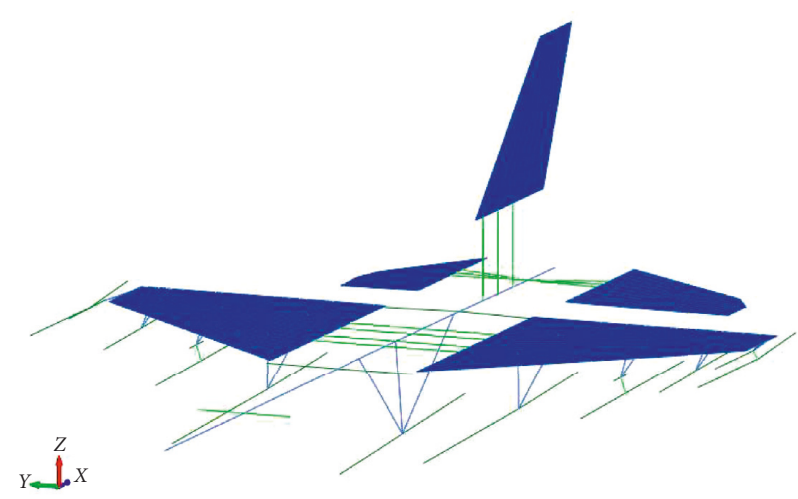

FIgURE 7: FE model with external loads.

where $[\varphi]$ are mass normalized eigenvectors and $\left[D_{\mathrm{e}}\right]$ is the diagonal matrix of eigenvalues.

For a mass modification of $[\Delta M]$,
TABLE 4: Mass constraints.

\begin{tabular}{lc}
\hline Mass area & Target value $(\mathrm{kg})$ \\
\hline Stations 1-9 & 195 \\
Stations 2-8 & 130 \\
Stations 3-7 & 935 \\
Stations 4-6 & 200 \\
Station 5 & 240 \\
Wing & 1000 \\
Horizontal stabilizer & 170 \\
Vertical stabilizer & 180 \\
Fuselage & 7600 \\
\hline
\end{tabular}

$$
\left([K]-\omega^{2}[M+\Delta M]\right)[\varphi]\{\eta\}=\{0\} .
$$

Multiply both sides with $[\varphi]^{T}$

$$
\left([\varphi]^{T}[K][\varphi]-\omega^{2}[\varphi]^{T}[M+\Delta M][\varphi]\right)[\varphi]\{\eta\}=\{0\} .
$$

Then

$$
\left(\left[D_{e}\right]-\omega^{2}\left([I]+[\varphi]^{T}[\Delta M][\varphi]\right)\right)\{\eta\}=\{0\} .
$$

The external loads are mounted to F-16 via adapters. They are connected to the adapters from a pair of assembly points or rails. The contact points on the adapters are tiny, and hence, external loads behave as connected rigid bodies with mass and rotary inertia in the frequency range of interest. In the calculations, only subtractive modificationof munition is applied as mass modification since the downloading (removal of external load) is frequently more critical for flutter than its takeoff loadingas well as being more practical in the GVT campaign [16]. Most importantly, it is also expected that stiffness values of the adapters will be the most critical issue in determining the response of the added munitions. The data will have to include the joint stiffness effect of such adapters which is challenging to model if the addition of munitions to unloaded GVT-based model is considered. Subtractive modification of external stores from a loaded model based on GVT will void the effect of joint stiffness which will not require the estimation of adapter stiffness, and this way, the results will be more accurate. The mass removal from the real test data with loaded configuration can be directly performed from the measurement points of the initial model. In the GVT process, the amount of mass of modification elements is relatively high when 
TABLE 5: Correlation data after model updating.

\begin{tabular}{ccccc}
\hline$\#$ & $\begin{array}{c}\text { Modal frequency before updating } \\
(\mathrm{Hz})\end{array}$ & $\begin{array}{c}\text { Modal frequency after updating } \\
(\mathrm{Hz})\end{array}$ & $\begin{array}{c}\text { Absolute \% difference of modal frequency from } \\
\text { FE and GVT results }(\%)\end{array}$ & $\begin{array}{c}\text { MAC } \\
(\%)\end{array}$ \\
\hline 1 & 3.30 & 3.84 & 0.02 & 9.01 \\
2 & 6.93 & 5.01 & 0.02 & 97.7 \\
3 & 7.46 & 5.48 & 0 & 97.6 \\
4 & 8.20 & 5.71 & 0.01 & 96.9 \\
5 & 8.34 & 6.86 & 0.01 & 93.7 \\
6 & 8.40 & 7.89 & 0.01 & 84.2 \\
7 & 10.33 & 8.90 & 0.01 & 80.6 \\
8 & 11.00 & 9.08 & 0.07 & 83.9 \\
9 & 11.07 & 9.74 & 0 & 82.9 \\
10 & 11.42 & 10.12 & & 35.9 \\
11 & 13.17 & 10.61 & & 0 \\
\hline
\end{tabular}

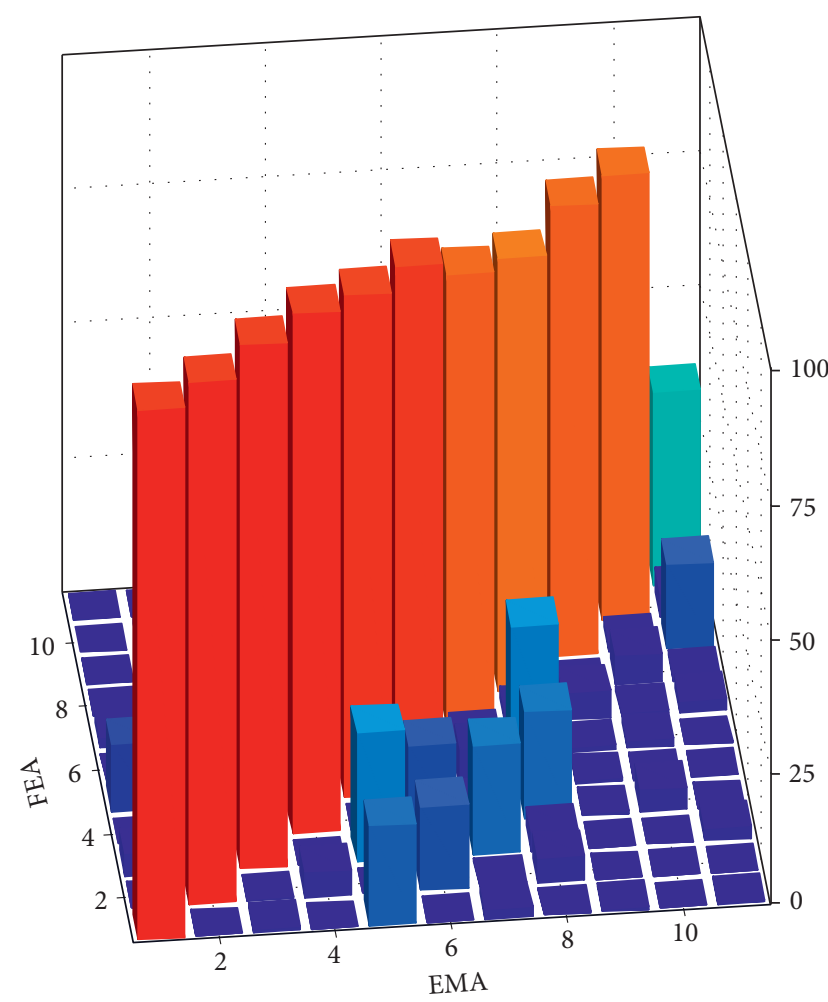

Figure 8: MAC matrix after updating.

compared to the mass of the wing. Additionally, the lengths of the stores are usually long when compared to the span of the wing and the length of the adapters. Moreover, rotary inertia of the munitions is so large that their effects must be included. In reality, mass, center of gravity (CG), and inertia terms of a new external store are available as early as the design phase which can be calculated based on the solid model so that they will be available during the planning of the test campaign.

In this approach, an additional measurement point at the CG location is synthesized by using the measurement points for the removal of an external store. The same nodes at CG of the removed external store can also be used to add the new external store and to use the design data of the new external store on the current real GVT test data by adding mass and inertia terms. In that case, the flexibility between the aircraft and the adapters can also be considered and the size of the matrix does not change.

In the determination of this synthetic point, translational measurements of measurement points on the removed load are used since the data from GVT will be available only in these degrees of freedom (DoFs). Additional four DoFs which are two translations and two rotations at CG position are added to the model instead of the two removed measurement points with two DoFs each. For example, by using the translational values in the $Z$ direction for measurement point 1 and point 2, location of CG position from the measurement point 1 and the length that is the value between the measurement points, the translation in the $Z$ direction at CG location can be calculated by

$$
T z_{\mathrm{CG}}=\frac{\left(T z_{2}-T z_{1}\right) x_{\mathrm{CG}}}{\text { length }}+T z_{1},
$$

where $T z_{\mathrm{CG}}$ stands for the translational value at CG position on $Z$ direction, $T z_{2}$ is for the translational value at measurement point 2 on $Z$ direction, $T z_{1}$ is for the translational value at measurement point 1 on $Z$ direction, and $x_{\mathrm{CG}}$ is the $x$ coordinate value of CG location. Similarly, for $Y$ direction,

$$
T y_{\mathrm{CG}}=\frac{\left(T y_{2}-T y_{1}\right) x_{\mathrm{CG}}}{\text { length }}+T y_{1} \text {. }
$$

Moreover, by using the right-hand rule, the rotation at CG will be

$$
R z_{\mathrm{CG}}=\frac{\left(T y_{2}-T y_{1}\right)}{\text { length }}
$$

Similarly, for $Y$ direction,

$$
R y_{\mathrm{CG}}=\frac{\left(T z_{1}-T z_{2}\right)}{\text { length }} \text {. }
$$

The nodes that are created at CG are used for the subtractive modification of mass effect. Not only the mass properties but also the inertia effects are removed in this manner. The eigenvectors that belong to the measurement points of the modification are removed from the eigenvector matrix, and synthetic CG node values are added to the same matrix. The matrix dimension does not change in this 


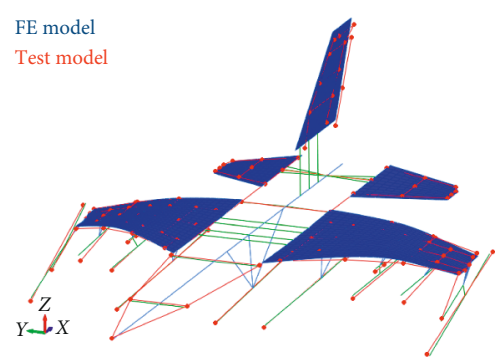

(a)

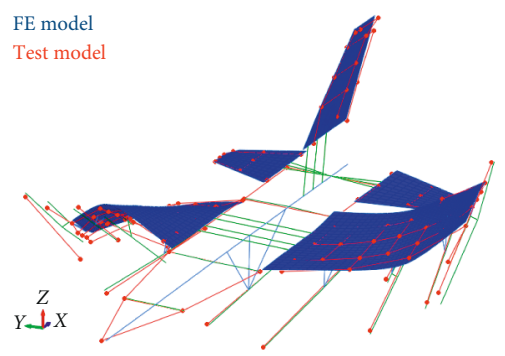

(d)

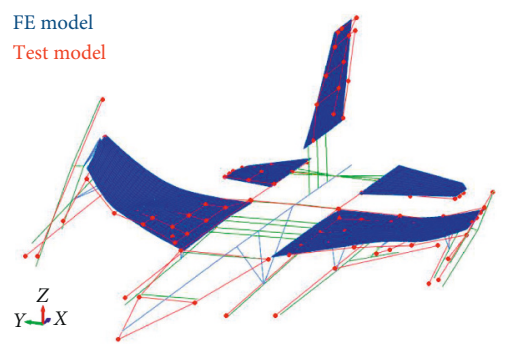

(g)

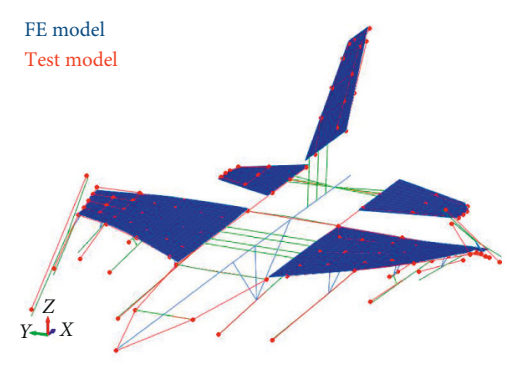

(b)

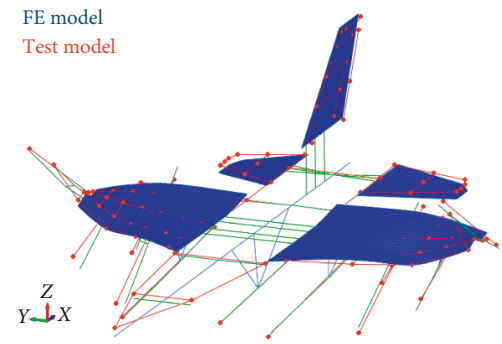

(e)

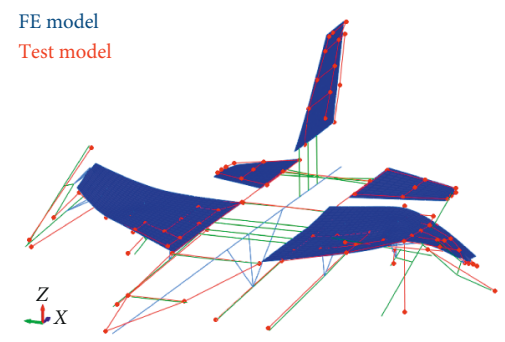

(h)

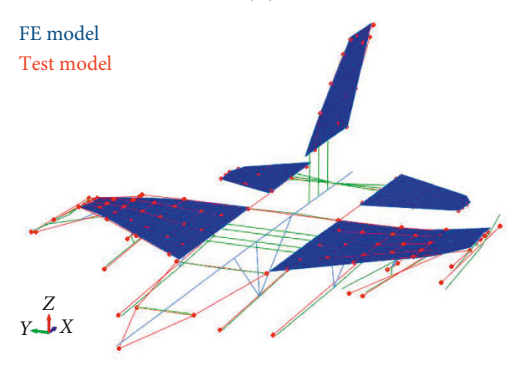

(j)

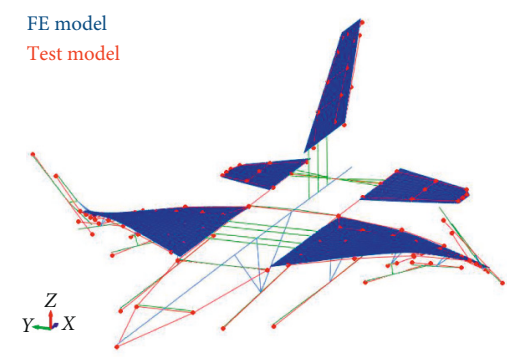

(c)

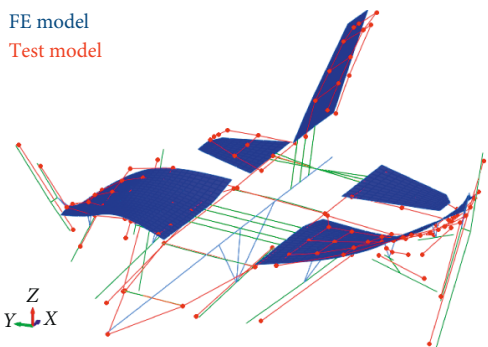

(f)

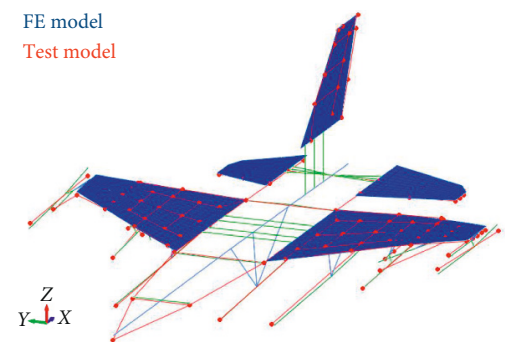

(i)

Figure 9: First 10 elastic modes (upper left to lower right): (a) mode 1, (b) mode 2, (c) mode 3, (d) mode 4, (e) mode 5, (f) mode 6, (g) mode 7, (h) mode 8, (i) mode 9, and (j) mode 10.

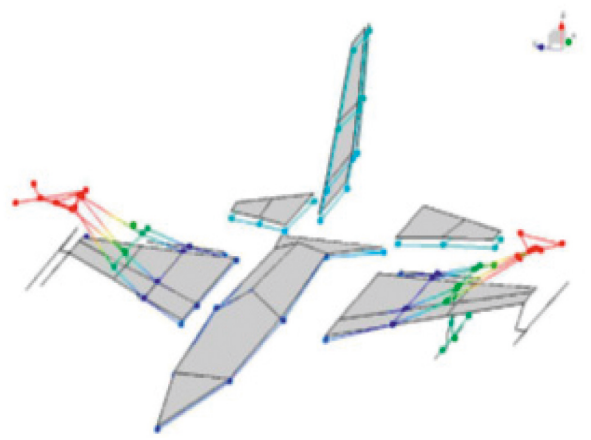

(a)

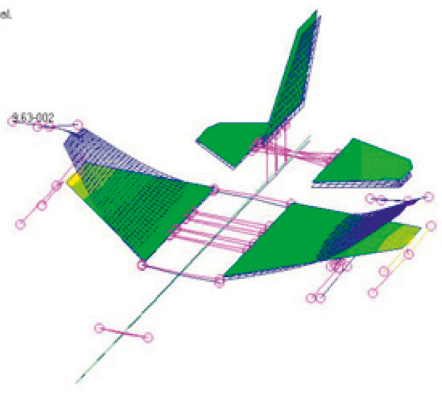

(b)

Figure 10: Continued. 


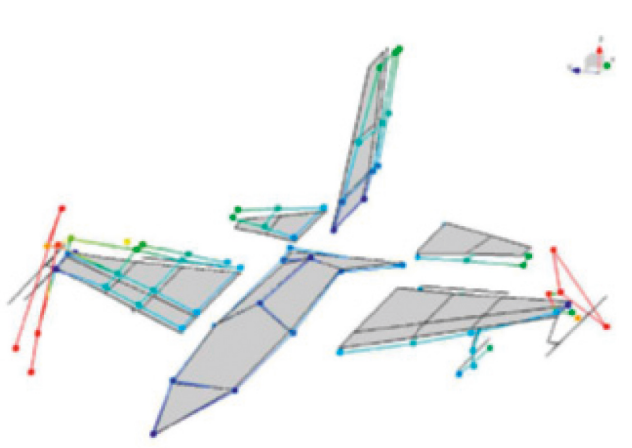

(c)

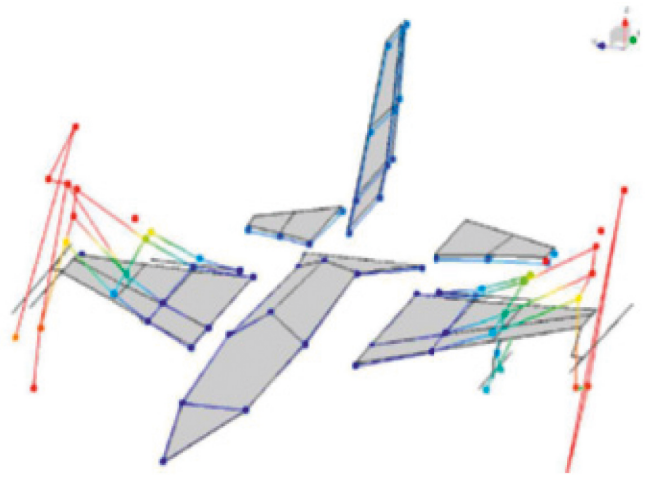

(e)

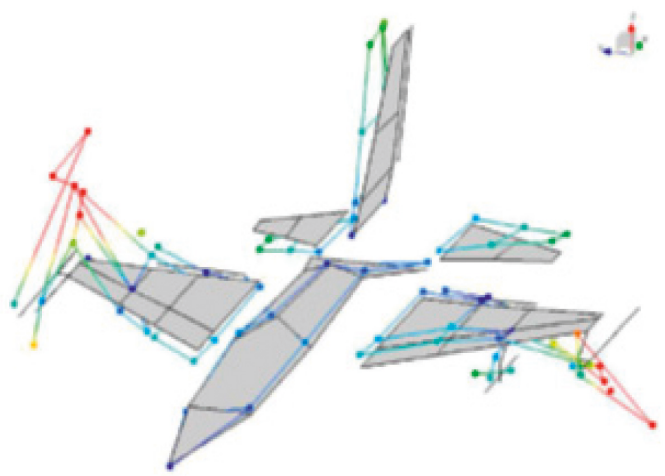

(g)

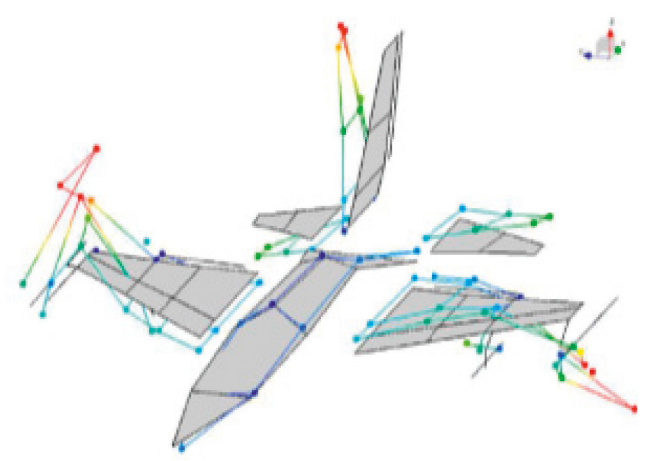

(i)

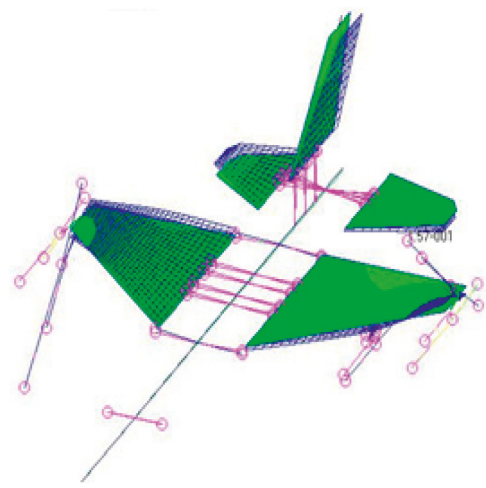

(d)

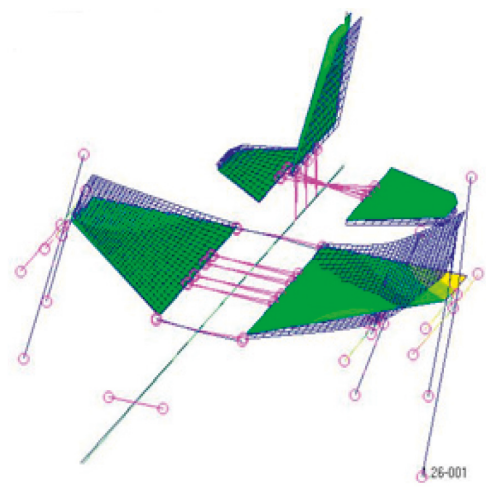

(f)

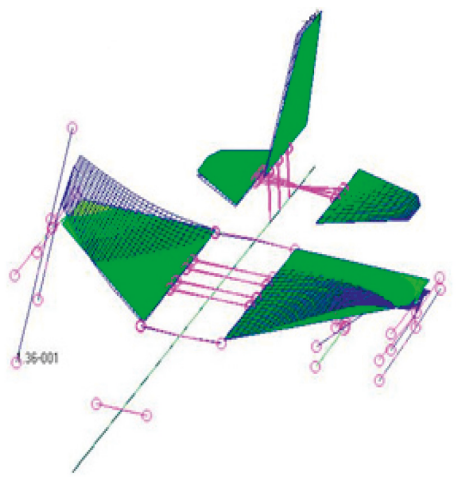

(h)

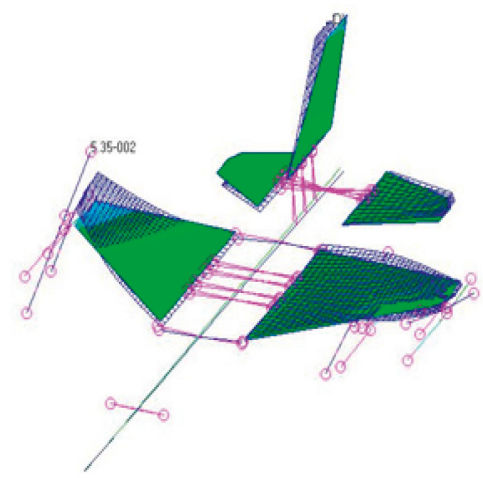

(j)

Figure 10: Verification of first five elastic modes (left: reference [16]; right: updated model): (a) mode 1-reference [11], (b) mode 1-updated model, (c) mode 2-reference [11], (d) mode 2-updated model, (e) mode 3-reference [11], (f) mode 3-updated model, (g) mode 4-reference [11], (h) mode 4-updated model, (i) mode 5-reference [11], and (j) mode 5-updated model. 
TABLE 6: Reference and updated model frequencies.

\begin{tabular}{lccc}
\hline Mode & Updated model frequency $(\mathrm{Hz})$ & Test model frequency $(\mathrm{Hz})$ & Percent error $(\%)$ \\
\hline 1 & 4.79 & 4.82 & 0.6 \\
2 & 6.23 & 6.18 & 0.8 \\
3 & 7.00 & 6.95 & 0.7 \\
4 & 7.82 & 7.78 & 0.5 \\
5 & 8.87 & 8.85 & 0.2 \\
\hline
\end{tabular}

approach. For the simulations, mass normalized eigenvectors are calculated as follows:

$$
\left[\varphi_{\mathrm{h}}\right]_{N x M}=\left[\varphi_{\mathrm{e}}\right]_{N x M}-\left[\varphi_{\mathrm{e}}\right]_{\text {Measure } x M}+\left[\varphi_{\mathrm{e}}\right]_{\text {Synth. } x M} .
$$

The modification mass and inertia terms are added to the respective rows of $[\Delta M]$ matrix.

\section{Simulations of Downloading Configurations}

Loading configurations for subtractive mass modification simulations are given in Table 7.

These configurations will be used to show the efficiency of this approach in the following sections. The parameters of stores for these configurations are provided in Table 8. It is imperative to understand three different model definitions given in the Introduction section.

5.1. Stations 1-9 (Configuration 1 vs. Configuration 3). In the case, AIM-120 is removed from station 1 . The natural frequencies for the initial/target models together with \% relative error and MAC matrix are given in Table 9 and Figure 11, respectively. The simulation is performed for the modification, and the results for natural frequencies are shown in Table 10.

The location-based error is also investigated only for this configuration. The error data are calculated for all DoFs as normalized to the maximum response DoF. The information can be used for tuning of the localized errors in simulation. The details of location-based error for different types of simulations might be studied later. The results are given through Figures 12-15 together with mode shapes. MAC for simulated/target models is also given in Figure 16.

5.2. Stations $2-8$ (Configuration 2 vs. Configuration 4 ). In this simulation, AIM-120 is replaced with AIM-9 in station 8. As in the first case, the natural frequencies for the initial/target models together with \% relative error and MAC matrix are given in Table 11 and Figure 17, respectively.

Simulation results for natural frequencies are presented in Table 12.

MAC for simulated/target models is given in Figure 18. First and second mode shapes of F-16 are also shown in Figures 19 and 20.

5.3. Stations 3-7 (Configuration 1 vs. Configuration 5). In the simulation, GBU31 munition is removed from station 3 as another type of modification. Similar to the previous presentation formation, the natural frequencies for the initial/ target models together with \% relative error and MAC matrix are given in Table 13 and Figure 21, respectively.

Results for simulation of natural frequencies are given in Table 14. First and second mode shapes of F-16 are shown in Figures 22 and 23 together with mode shapes. MAC for simulated/target models is also given in Figure 24.

\section{Effect of Fuel}

The effect of fuel is demonstrated for the fuel in the fuselage and underwing tanks. Mass addition strategy is performed for analysis in contrast to the store loading cases since filling the F-16 fuel tanks in the GVT campaign is simpler than draining in practice. In the real case, the aircraft consumes fuel throughout the flight. The black fuel tanks seen in Figure 25 are taken as full, and although the gray tanks are not full, they contain fuel. The white sections do not contain any fuel. Fuel is added to the current nodes as lumped mass for modification.

6.1. Configuration 3 Low/Medium Fuel Level. In this case, F-16 contains fuel in the fuselage tanks. In the low configuration, approximately $500 \mathrm{lb}$ of fuel is present in each of the right and left reservoirs, approximately $1300 \mathrm{lb}$ in F-1, F-2, and A-1 tanks and approximately $100 \mathrm{lb}$ in both internal wing tanks as shown in Figure 25. In the medium configuration, there is approximately $500 \mathrm{lb}$ of fuel in each of the right and left reservoirs, approximately $3600 \mathrm{lb}$ in F-1, F-2, and A-1 tanks and approximately $100 \mathrm{lb}$ in both internal wing tanks. The natural frequencies with \% relative error are shown in Table 15.

MAC matrix for initial-target and simulated-target models is shown in Figures 26 and 27, respectively.

Table 16 shows the calculated values by the simulations. Mode shapes are also given for fuel modification cases in Figures 28 and 29.

6.2. Configuration 1 Low/Medium Fuel Level. In this case, F-16 contains fuel in both the fuselage and underwing external fuel tanks. The location of fuel in the underwing external fuel tanks affects the flutter characteristics of F-16 [17]. The flutter speed increases when the fuel is initially consumed from the middle section. Although the low fuel case is similar to the case in the previous section, $1350 \mathrm{lb}$ of fuel is present in the front and aft sections of the fuel tank. The selection of location is performed by taking the flutter testing requirements into account as given in Figure 30.

The natural frequencies with $\%$ relative error are shown in Table 17 for the simulation. MAC matrix for initial-target 
TABLE 7: Loading configurations.

\begin{tabular}{lccccc}
\hline$\#$ & Configuration 1 & Configuration 2 & Configuration 3 & Configuration 4 & Configuration 5 \\
\hline 1 & AA1 & AA1 & LAU-129 & AA1 & AA1 \\
2 & AA2 & AA1 & AA2 & AA1 & AA2 \\
3 & GBU31 & GBU31 & GBU31 & GBU31 & Tank-1 \\
4 & Tank-1 & Tank-1 & P-1 & P-1 & P-1 \\
$5 \mathrm{~L}$ & P-1 & P-1 & Tank-2 & Tank-2 & P-2 \\
5 & Tank-2 & Tank-2 & P-2 & Tank-1 & P-2 \\
$5 \mathrm{R}$ & P-2 & Tank-1 & Tank-1 & GBU31 & GBU31 \\
6 & Tank-1 & GBU31 & AAU31 & AA2 & AA2 \\
7 & GBU31 & AA1 & AA1 & AA1 & AA1 \\
8 & AA2 & AA1 & & & \\
9 & AA1 & & & &
\end{tabular}

TABLE 8: Loads and locations.

\begin{tabular}{|c|c|c|c|c|c|}
\hline Load and location & Mass (kg) & CG from nose $(\mathrm{m})$ & Length $(\mathrm{m})$ & Yaw inertia $\left(\mathrm{kgm}^{2}\right)$ & Pitch inertia $\left(\mathrm{kgm}^{2}\right)$ \\
\hline LAU-129 (WTR\&WTL) & 39.5 & - & 3.44 & 18.8 & 18.8 \\
\hline AIM-120 (A120R\&A120L) & 156 & 2.1 & 2.37 & 131 & 131 \\
\hline 16 S210 (ULR\&ULL) & 31 & - & 2.62 & 15.8 & 15.8 \\
\hline 16S301 (ULR\&ULL) & 9 & - & - & - & - \\
\hline AIM-9 (ULR\&ULL) & 91 & 1.8 & 2.62 & 70 & 70 \\
\hline $16 S 1700$ (MPR\&MPL) & 161 & - & 1.54 & 19.4 & 18.3 \\
\hline GBU31 JDAM (MR\&ML) & 934 & 1.59 & 3.65 & 553 & 553 \\
\hline 370 gal fuel tank (DR\&DL) & 199 & 2.32 & 5.45 & 239 & 225 \\
\hline 300 gal fuel tank (CL) & 242 & 2.2 & 4.42 & 224 & 224 \\
\hline AAQ-13 & 204 & - & - & - & - \\
\hline AAQ-14 & 249 & - & - & - & - \\
\hline
\end{tabular}

TABLE 9: Natural frequencies for configuration 1 vs. configuration 3.

\begin{tabular}{lccc}
\hline Mode & Initial model frequency $(\mathrm{Hz})$ & Target model frequency $(\mathrm{Hz})$ & \% relative error \\
\hline 1 & 3.84 & 4.28 & 10.24 \\
2 & 5.01 & 5.44 & 7.87 \\
3 & 5.48 & 6.23 & 11.95 \\
4 & 5.71 & 6.45 & 11.53 \\
5 & 6.86 & 7.98 & 14.05 \\
6 & 7.89 & 8.94 & 11.75 \\
7 & 8.90 & 9.50 & 6.22 \\
8 & 9.08 & 9.65 & 5.91 \\
9 & 9.74 & 10.57 & 7.81 \\
10 & 10.12 & 10.68 & 5.25 \\
11 & 10.61 & 11.17 & 5.02 \\
12 & 11.20 & 11.82 & 5.26 \\
13 & 11.31 & 11.91 & 5.05 \\
14 & 11.93 & 12.34 & 3.30 \\
15 & 12.03 & 13.08 & 8.02 \\
16 & 12.67 & 13.14 & 3.57 \\
\end{tabular}

and simulated-target models is shown in Figures 31 and 32, respectively.

Table 18 shows the calculated values of the simulations. Mode shapes are also given for fuel modification case in Figures 33 and 34 .

\section{Results and Discussion}

The simulations are performed for different loading stations and fuel conditions of F-16. Effect of AIM-120 AMRAAM munition is examined for loading station 1.10-11 modes are simulated correctly with less than $3 \%$ error of prediction in natural frequencies. The location-based error is also studied for this configuration. The error data are calculated for all DoFs as normalized to the maximum response DoF and calculated as $3 \%$. The data can be used to tune the model in detail. In station 2, AIM-120 AMRAAM is replaced with AIM-9 Sidewinder to show the effect of the modification. Initially, the models are well correlated up to six modes and better than that, the simulations predicted the modified 


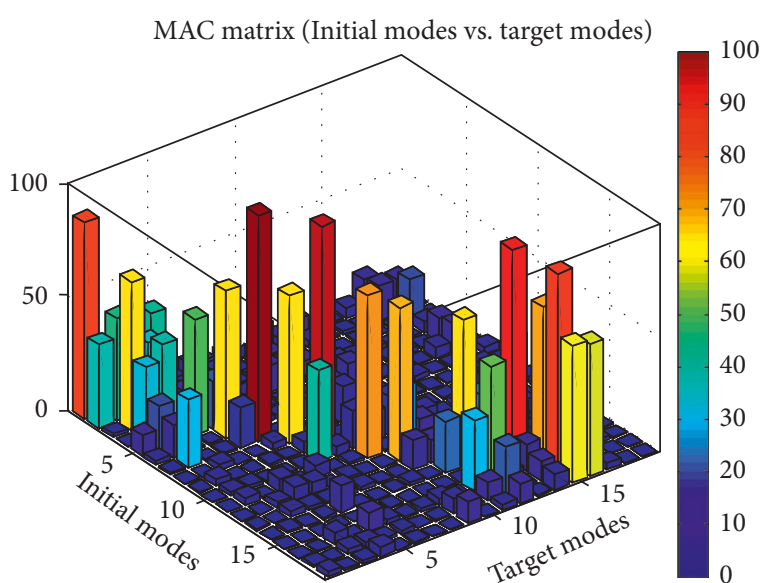

FIgURE 11: MAC of configuration 1 vs. configuration 3.

TABLe 10: Natural frequencies for configuration 3.

\begin{tabular}{lccc}
\hline Mode & $\begin{array}{c}\text { Initial model } \\
\text { frequency }(\mathrm{Hz})\end{array}$ & $\begin{array}{c}\text { Target model } \\
\text { frequency }(\mathrm{Hz})\end{array}$ & \% relative error \\
\hline 1 & 4.27 & 4.28 & 0.24 \\
2 & 5.47 & 5.44 & 0.56 \\
3 & 6.21 & 6.23 & 0.16 \\
4 & 6.47 & 6.45 & 0.32 \\
5 & 7.89 & 7.98 & 1.15 \\
6 & 8.90 & 8.94 & 0.34 \\
7 & 9.43 & 9.50 & 0.64 \\
8 & 9.75 & 9.65 & 1.06 \\
9 & 10.49 & 10.57 & 0.68 \\
10 & 10.74 & 10.68 & 0.57 \\
11 & 11.01 & 11.17 & 1.37 \\
12 & 11.54 & 11.82 & 2.33 \\
13 & 11.94 & 11.91 & 0.26 \\
14 & 12.04 & 12.34 & 2.39 \\
15 & 12.92 & 13.08 & 1.25 \\
16 & 12.99 & 13.14 & 1.16 \\
17 & 13.39 & 13.42 & 0.23 \\
\hline
\end{tabular}

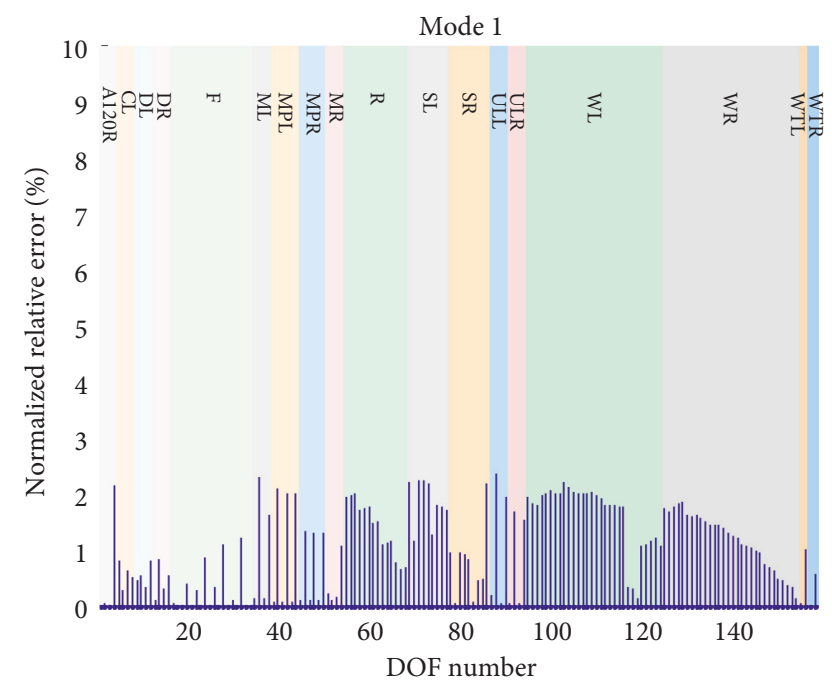

Figure 12: Normalized error location on F-16 for configuration 3 mode-1.

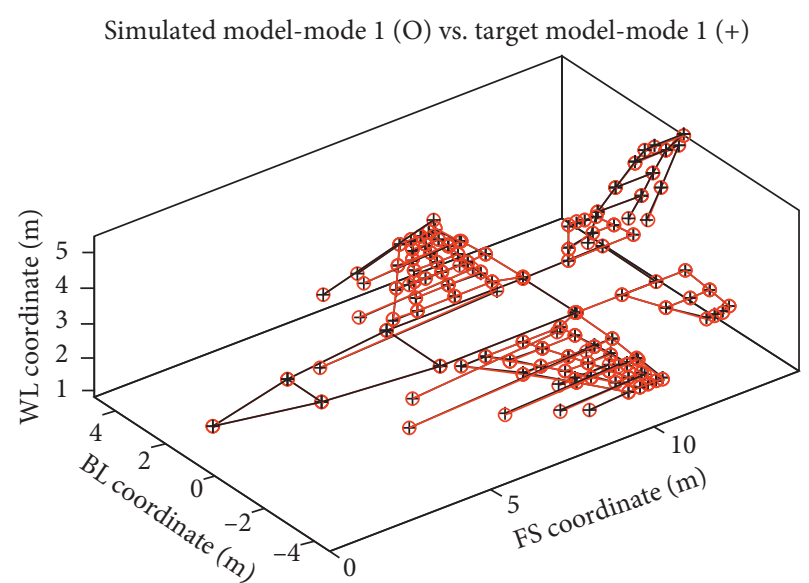

FIgURE 13: Mode shape for configuration 3 mode-1.

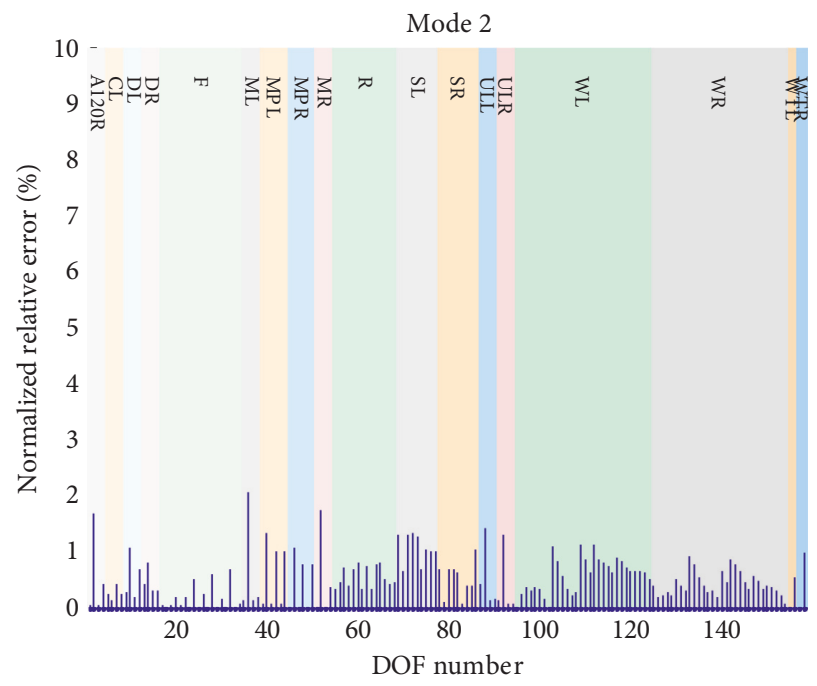

FIGURE 14: Normalized error location on F-16 for configuration 3 mode-2.

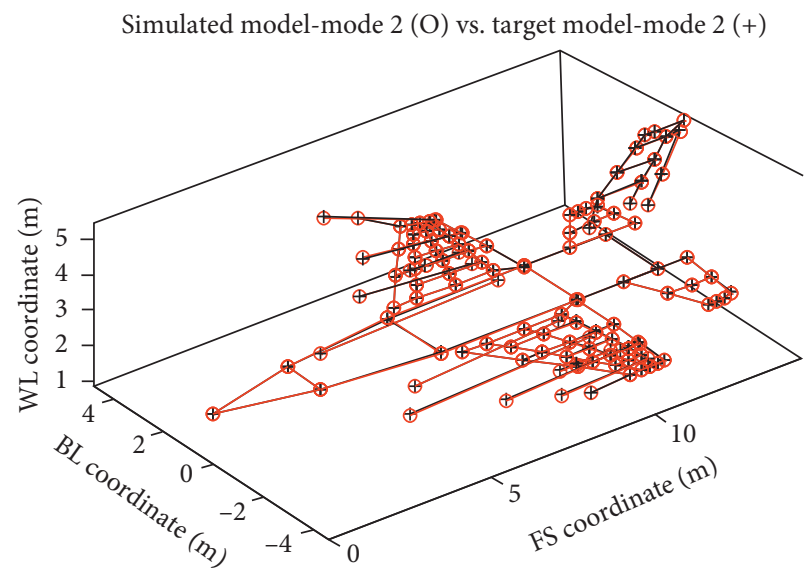

FIGURE 15: Mode shape for configuration 3 mode- 2.

response up to ten modes. All the error values are below $2 \%$ for the natural frequencies. GBU31 is directly removed from station 3 as the main change in mass distribution. Four 


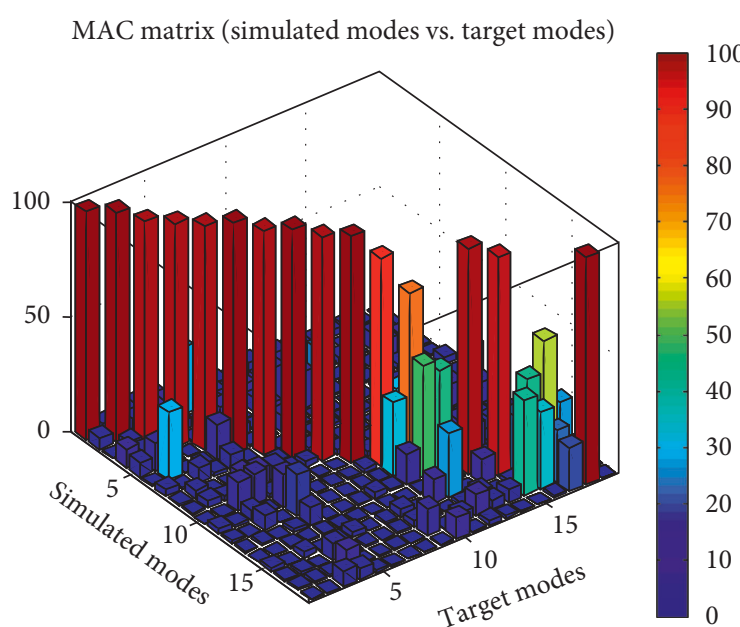

Figure 16: MAC of configuration 3.
TABLE 12: Natural frequencies for configuration 4.

\begin{tabular}{lccc}
\hline Mode & $\begin{array}{c}\text { Initial model } \\
\text { frequency }(\mathrm{Hz})\end{array}$ & $\begin{array}{c}\text { Target model } \\
\text { frequency }(\mathrm{Hz})\end{array}$ & \% relative error \\
\hline 1 & 3.73 & 3.76 & 0.81 \\
2 & 4.89 & 4.90 & 0.21 \\
3 & 5.32 & 5.30 & 0.38 \\
4 & 5.71 & 5.60 & 2.00 \\
5 & 7.75 & 7.79 & 0.39 \\
6 & 8.50 & 8.43 & 0.84 \\
7 & 8.84 & 8.85 & 0.11 \\
8 & 9.02 & 9.04 & 0.22 \\
9 & 9.76 & 9.87 & 1.13 \\
10 & 10.41 & 10.54 & 1.25 \\
11 & 10.53 & 11.01 & 4.34 \\
12 & 10.99 & 11.16 & 1.55 \\
13 & 11.46 & 11.51 & 0.35 \\
14 & 11.69 & 11.90 & 1.79 \\
15 & 12.37 & 12.20 & 1.42 \\
16 & 13.30 & 12.78 & 4.14 \\
\hline
\end{tabular}

TABLE 11: Natural frequencies for configuration 2 vs. configuration 4.

\begin{tabular}{lccc}
\hline Mode & $\begin{array}{c}\text { Initial model } \\
\text { frequency }(\mathrm{Hz})\end{array}$ & $\begin{array}{c}\text { Target model } \\
\text { frequency }(\mathrm{Hz})\end{array}$ & \% relative error \\
\hline 1 & 3.71 & 3.76 & 1.35 \\
2 & 4.86 & 4.90 & 0.83 \\
3 & 5.21 & 5.30 & 1.54 \\
4 & 5.50 & 5.60 & 1.81 \\
5 & 7.74 & 7.79 & 0.52 \\
6 & 8.50 & 8.43 & 0.84 \\
7 & 8.71 & 8.85 & 1.61 \\
8 & 8.97 & 9.04 & 0.67 \\
9 & 9.51 & 9.87 & 3.60 \\
10 & 9.75 & 10.54 & 7.52 \\
11 & 10.16 & 11.01 & 7.66 \\
12 & 10.76 & 11.16 & 3.55 \\
13 & 11.45 & 11.51 & 0.44 \\
14 & 11.56 & 11.90 & 2.90 \\
15 & 12.24 & 12.20 & 0.33 \\
16 & 13.26 & 12.78 & 3.82 \\
\hline
\end{tabular}

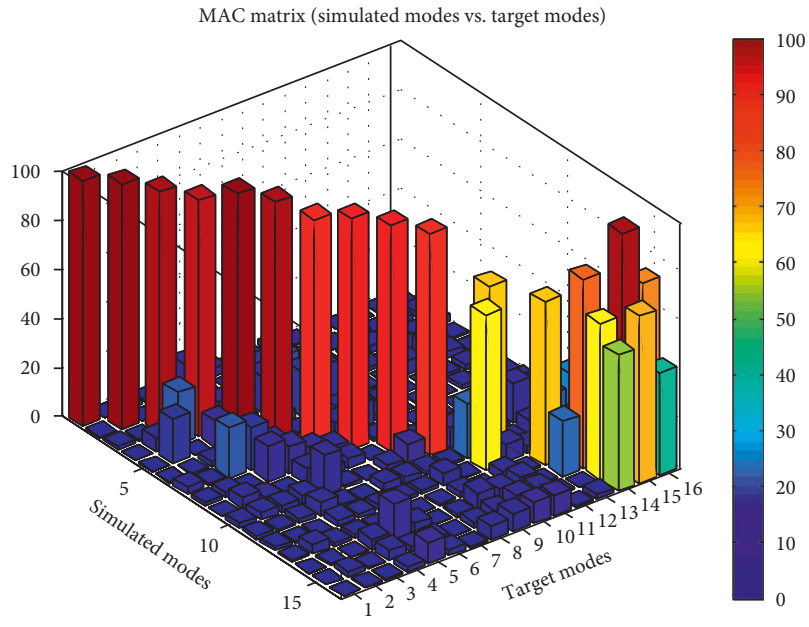

Figure 18: MAC of configuration 4.

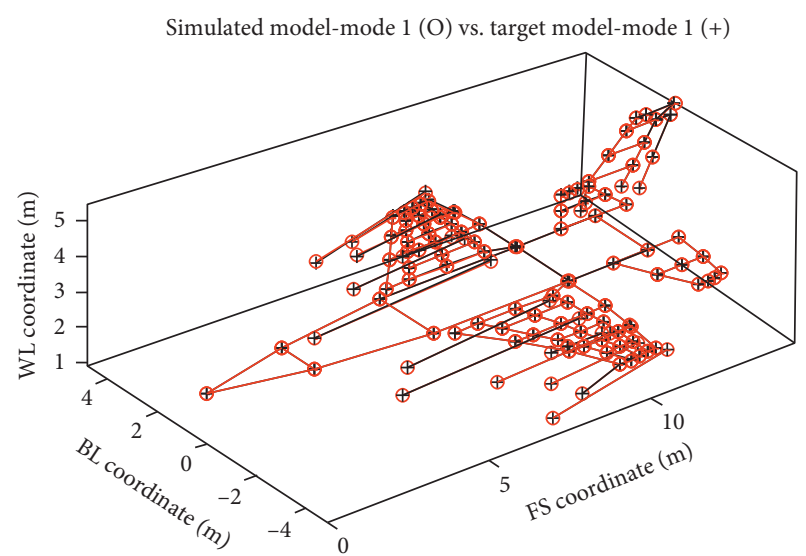

FIgURe 19: Mode shape for configuration 4 mode-1.

Figure 17: Mode shape for configuration 2 vs. configuration 4. 


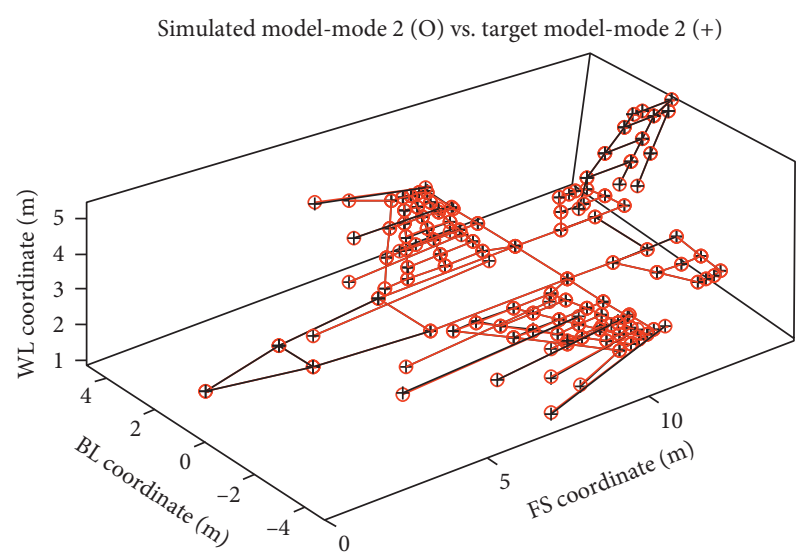

Figure 20: Mode shape for configuration 4 mode-2.
TABLE 14: Natural frequencies for configuration 5.

\begin{tabular}{lccc}
\hline Mode & $\begin{array}{c}\text { Initial model } \\
\text { frequency }(\mathrm{Hz})\end{array}$ & $\begin{array}{c}\text { Target model } \\
\text { frequency }(\mathrm{Hz})\end{array}$ & \% relative error \\
\hline 1 & 3.90 & 3.60 & 8.50 \\
2 & 4.96 & 4.73 & 4.96 \\
3 & 5.52 & 5.35 & 3.24 \\
4 & 5.84 & 5.96 & 2.05 \\
5 & 6.97 & 6.49 & 7.38 \\
6 & 8.15 & 8.06 & 1.14 \\
7 & 8.96 & 8.62 & 3.90 \\
8 & 9.18 & 9.18 & 0.00 \\
9 & 9.52 & 9.28 & 2.52 \\
10 & 10.03 & 9.50 & 5.58 \\
11 & 10.64 & 10.13 & 5.03 \\
12 & 10.95 & 10.48 & 4.47 \\
13 & 11.18 & 10.87 & 2.81 \\
14 & 11.38 & 10.97 & 3.71 \\
\hline
\end{tabular}

TABLE 13: Natural frequencies for configuration 1 vs. configuration 5.

\begin{tabular}{lccc}
\hline Mode & $\begin{array}{c}\text { Initial model } \\
\text { frequency }(\mathrm{Hz})\end{array}$ & $\begin{array}{c}\text { Target model } \\
\text { frequency }(\mathrm{Hz})\end{array}$ & $\begin{array}{c}\text { \% relative } \\
\text { error }\end{array}$ \\
\hline 1 & 3.81 & 3.60 & 5.95 \\
2 & 4.93 & 4.73 & 4.31 \\
3 & 5.43 & 5.35 & 1.52 \\
4 & 5.51 & 5.96 & 7.52 \\
5 & 6.71 & 6.49 & 3.45 \\
6 & 7.73 & 8.06 & 4.05 \\
7 & 8.48 & 8.62 & 1.65 \\
8 & 8.86 & 9.18 & 3.44 \\
9 & 9.12 & 9.28 & 1.76 \\
10 & 9.46 & 9.50 & 0.43 \\
11 & 9.97 & 10.13 & 1.51 \\
12 & 10.29 & 10.48 & 1.85 \\
13 & 10.87 & 10.87 & 0.00 \\
14 & 11.13 & 10.97 & 1.39 \\
\hline
\end{tabular}

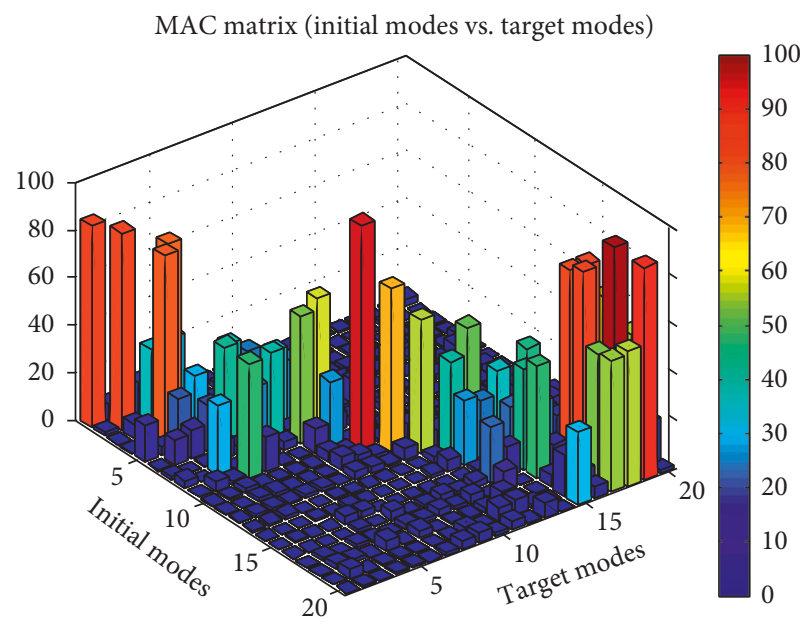

FIgURe 21: Mode shape for configuration 1 vs. configuration 5.

modes are correlated to the target, and the results are elaborated to be used for GVT planning and even in preliminary flutter analyses.

Addition of fuel strategy is used for the calculations in this study. The fuel is added to the current nodes as point

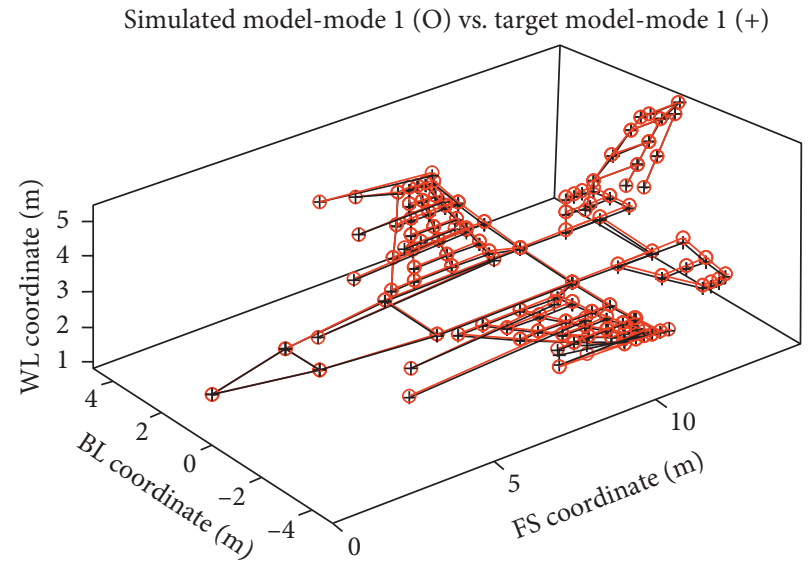

FIgURe 22: Mode shape for configuration 5 mode-1.

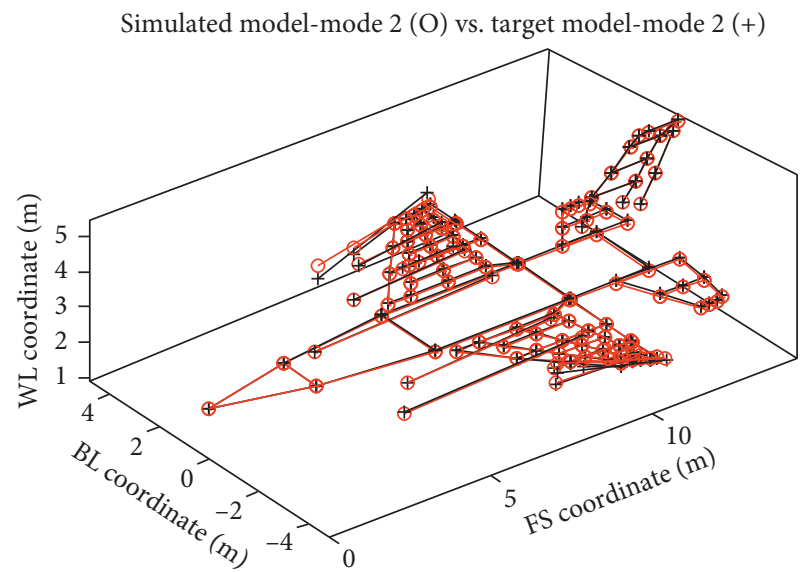

FIgURE 23: Mode shape for configuration 5 mode-2.

masses. It is shown that the effect of the change in fuel level on the fuselage fuel tanks can be precisely predicted by this approach. The number of modes that can be predicted by the simulation is found as seventeen in the study. Fuel in underwing fuel tanks may have more effect on the structural 


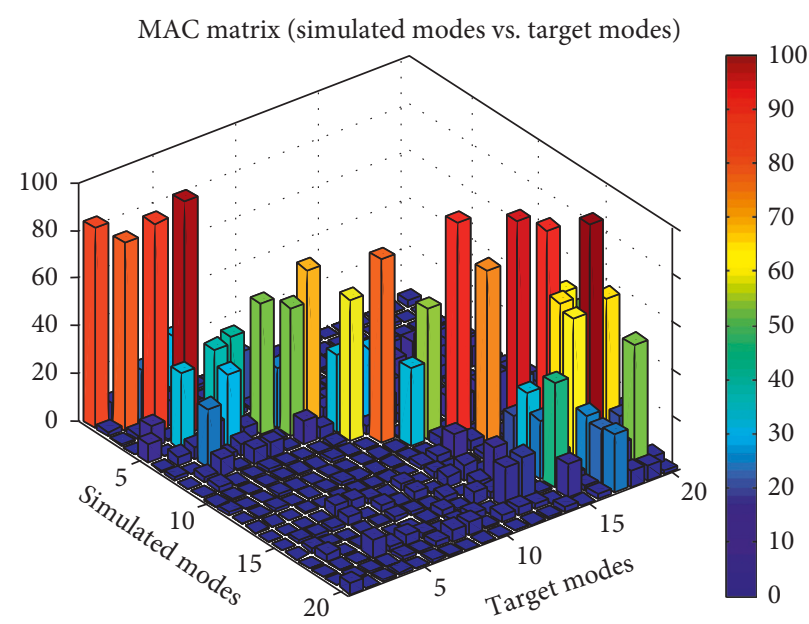

FIgURE 24: MAC of configuration 5.

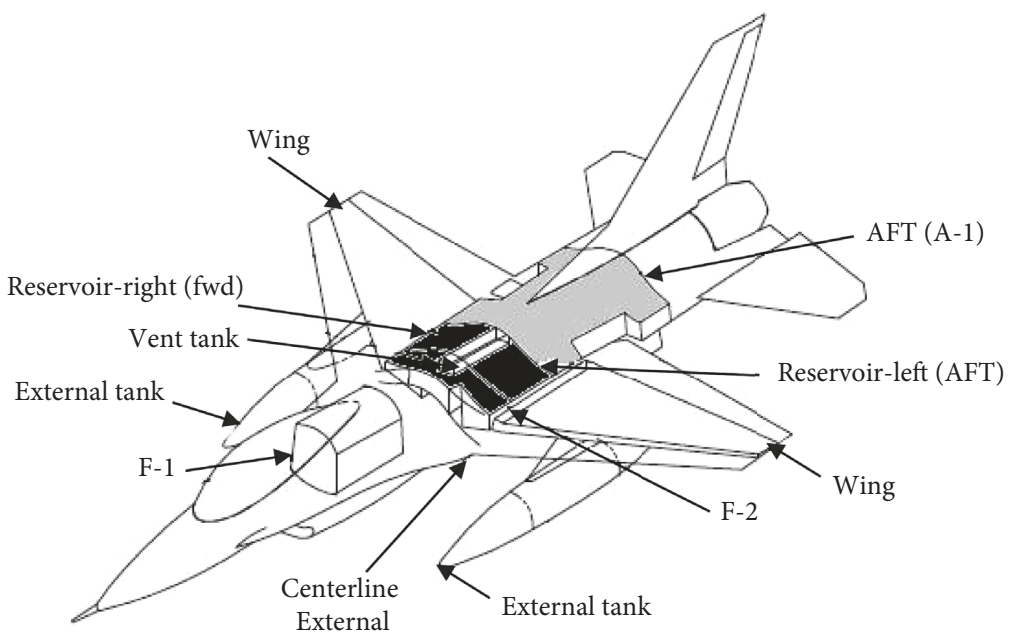

Figure 25: Low and medium fuel locations.

TABLE 15: Fuel configurations for configuration 3.

\begin{tabular}{lccc}
\hline Mode & $\begin{array}{c}\text { Initial model } \\
\text { frequency }(\mathrm{Hz})\end{array}$ & $\begin{array}{c}\text { Target model } \\
\text { frequency }(\mathrm{Hz})\end{array}$ & \% relative error \\
\hline 1 & 4.28 & 4.19 & 2.19 \\
2 & 5.44 & 5.43 & 0.19 \\
3 & 6.23 & 6.21 & 0.16 \\
4 & 6.45 & 6.41 & 0.64 \\
5 & 7.98 & 7.74 & 3.03 \\
6 & 8.94 & 8.91 & 0.23 \\
7 & 9.50 & 9.55 & 0.53 \\
8 & 9.65 & 9.71 & 0.63 \\
9 & 10.57 & 10.19 & 3.70 \\
10 & 10.68 & 10.63 & 0.48 \\
11 & 11.17 & 11.00 & 1.48 \\
12 & 11.82 & 11.22 & 5.36 \\
13 & 11.91 & 11.82 & 0.78 \\
14 & 12.34 & 11.99 & 2.89 \\
15 & 13.08 & 12.71 & 2.97 \\
16 & 13.14 & 13.30 & 1.15 \\
17 & 13.42 & 13.75 & 2.44 \\
\hline
\end{tabular}

dynamics, but only six modes have been simulated in this paper. The error for natural frequencies is $1 \%$ at most, so the results can be used for input data in a following flutter analysis.

In the view of such information, test configurations for GVT planning can be determined in two ways. In terms of GVT, test configurations can be selected depending on the loading station and level of accuracy of the simulated model. If the results of simulated models can be verified in the frequency range of interest by previous GVT results, then that high-fidelity models can be used to generate predicted GVT data to be used in preliminary analyses. For example, the effect of fuel in fuselage tanks is shown to have no effect on the structural dynamics of F-16. The dynamics of the aircraft can be fully simulated for that change by this approach. The approach is applied to real GVT result data which show that minimization of the total number of test configurations and testing time is possible approximately to $80 \%$.

Test configurations can be mainly selected by the results of preliminary flutter analyses. Predicted GVT data or 


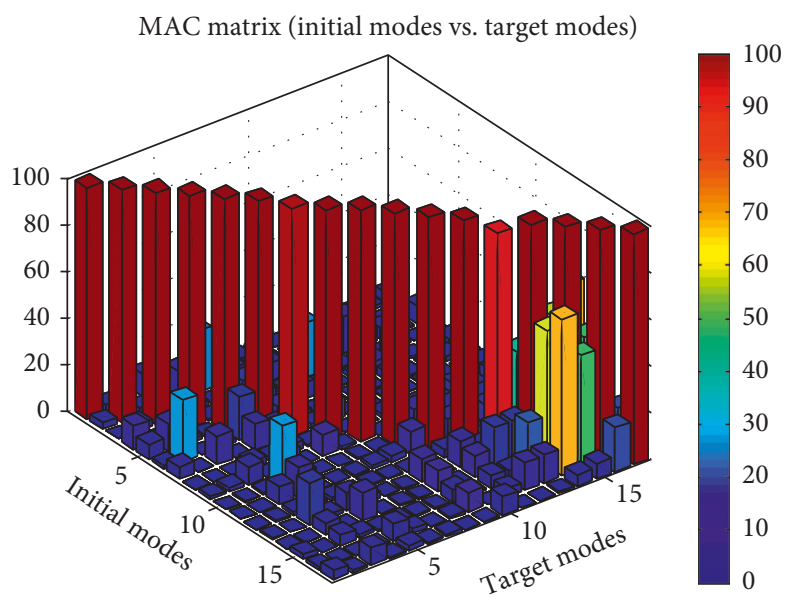

Figure 26: MAC of configuration 3 initial-target model.

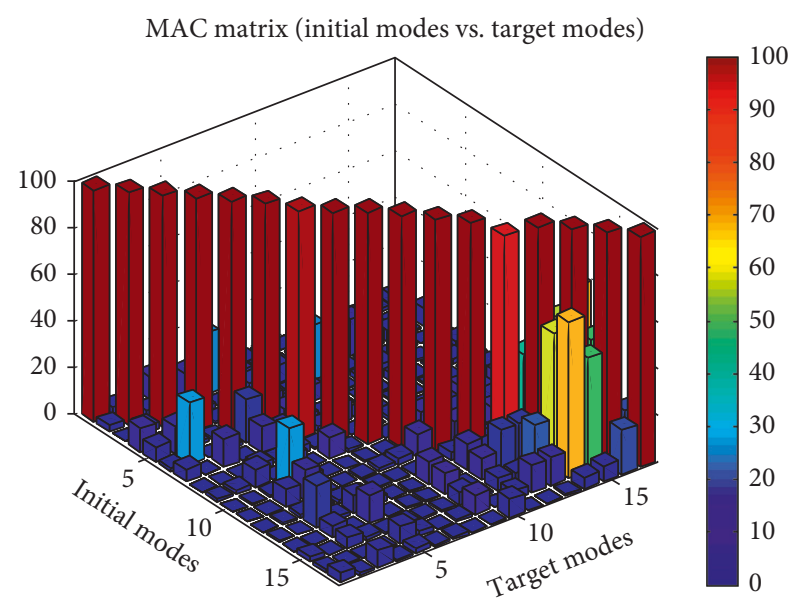

FIGURE 27: MAC of configuration 3 simulated-target model.

TABLE 16: Fuel configurations for configuration 3 simulation.

\begin{tabular}{lccc}
\hline Mode & $\begin{array}{c}\text { Initial model } \\
\text { frequency }(\mathrm{Hz})\end{array}$ & $\begin{array}{c}\text { Target model } \\
\text { frequency }(\mathrm{Hz})\end{array}$ & \% relative error \\
\hline 1 & 4.25 & 4.19 & 1.46 \\
2 & 5.43 & 5.43 & 0.00 \\
3 & 6.19 & 6.21 & 0.33 \\
4 & 6.44 & 6.41 & 0.48 \\
5 & 7.89 & 7.74 & 1.84 \\
6 & 8.93 & 8.91 & 0.11 \\
7 & 9.49 & 9.55 & 0.64 \\
8 & 9.64 & 9.71 & 0.73 \\
9 & 10.54 & 10.19 & 3.40 \\
10 & 10.66 & 10.63 & 0.29 \\
11 & 11.08 & 11.00 & 0.65 \\
12 & 11.77 & 11.22 & 4.90 \\
13 & 11.84 & 11.82 & 0.17 \\
14 & 12.31 & 11.99 & 2.63 \\
15 & 13.06 & 12.71 & 2.81 \\
16 & 13.11 & 13.30 & 1.38 \\
17 & 13.38 & 13.75 & 2.74 \\
\hline
\end{tabular}

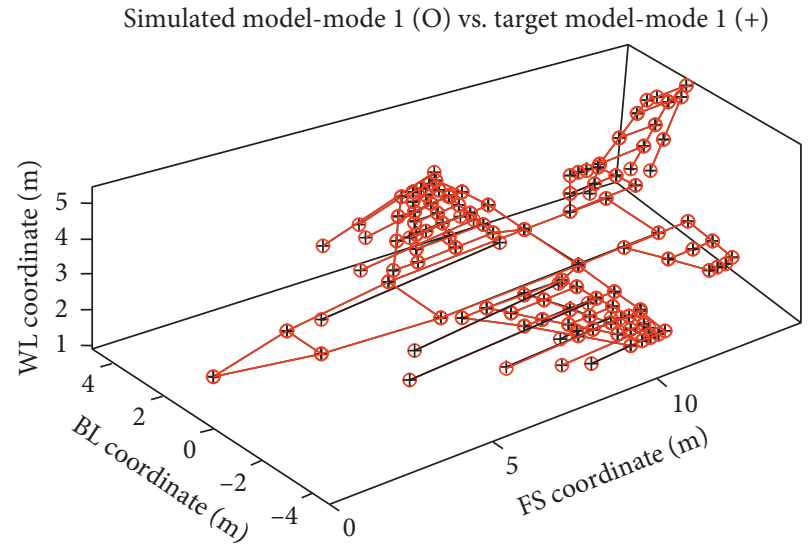

FIgURE 28: Mode shape for configuration 3 mode-1.

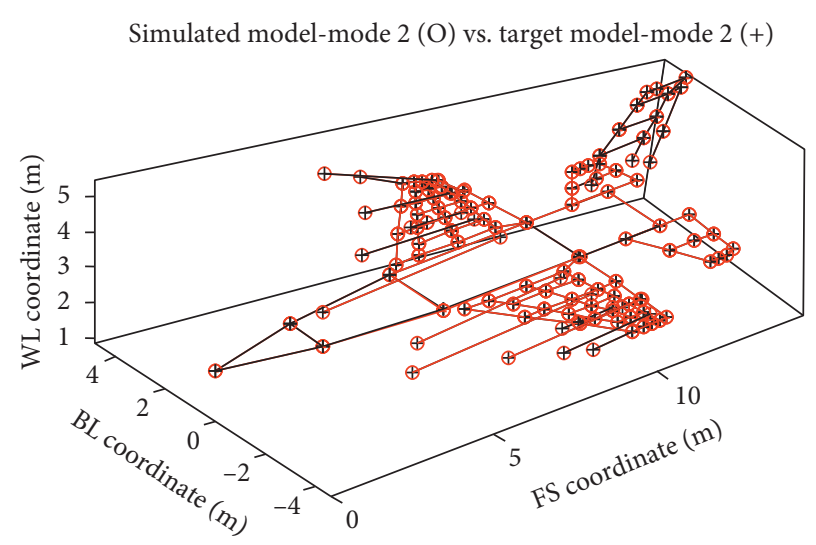

FIgURE 29: Mode shape for configuration 3 mode-2.

updated models for the draft test matrix can be used for preliminary flutter analyses. If the results of preliminary flutter analyses seem critical, then that configurations can be added to the test sequence in GVT planning. 


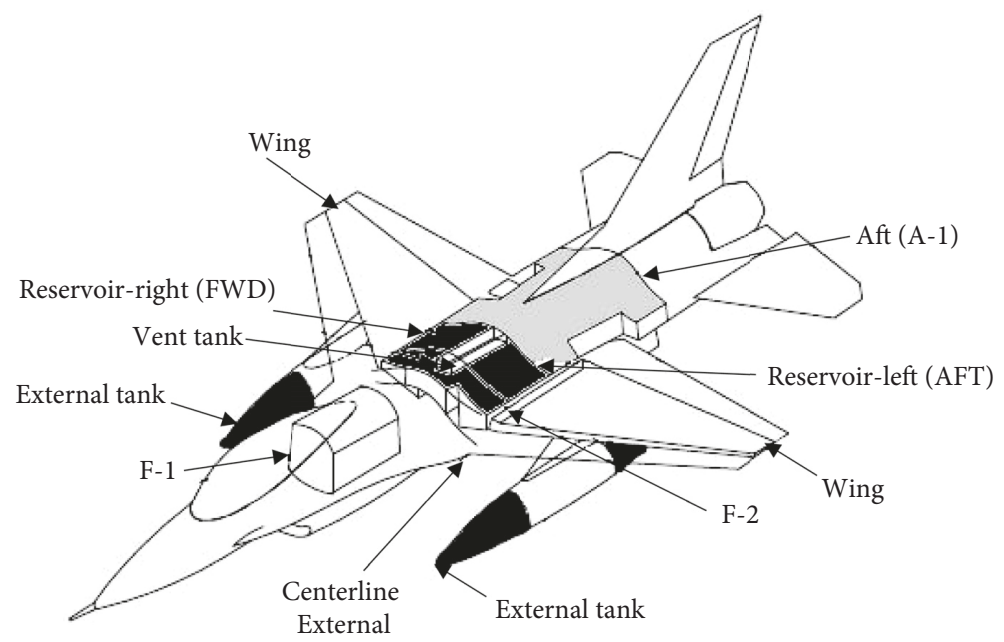

FIGURE 30: High fuel locations.

TABLE 17: Fuel configurations for configuration 1.

\begin{tabular}{lccc}
\hline Mode & $\begin{array}{c}\text { Initial model } \\
\text { frequency }(\mathrm{Hz})\end{array}$ & $\begin{array}{c}\text { Target model } \\
\text { frequency }(\mathrm{Hz})\end{array}$ & \% relative error \\
\hline 1 & 3.84 & 3.82 & 0.53 \\
2 & 5.01 & 4.94 & 1.44 \\
3 & 5.48 & 5.44 & 0.75 \\
4 & 5.71 & 5.52 & 3.32 \\
5 & 6.86 & 6.72 & 1.97 \\
6 & 7.89 & 7.74 & 1.84 \\
7 & 8.90 & 8.49 & 4.92 \\
8 & 9.08 & 8.88 & 2.18 \\
9 & 9.74 & 9.14 & 6.58 \\
10 & 10.12 & 9.47 & 6.89 \\
11 & 10.61 & 10.00 & 6.12 \\
12 & 11.20 & 10.31 & 8.60 \\
13 & 11.31 & 10.89 & 3.84 \\
14 & 11.93 & 11.15 & 7.04 \\
15 & 12.03 & 11.36 & 5.92 \\
16 & 12.67 & 11.43 & 10.87 \\
17 & 12.95 & 12.03 & 7.62 \\
\hline
\end{tabular}

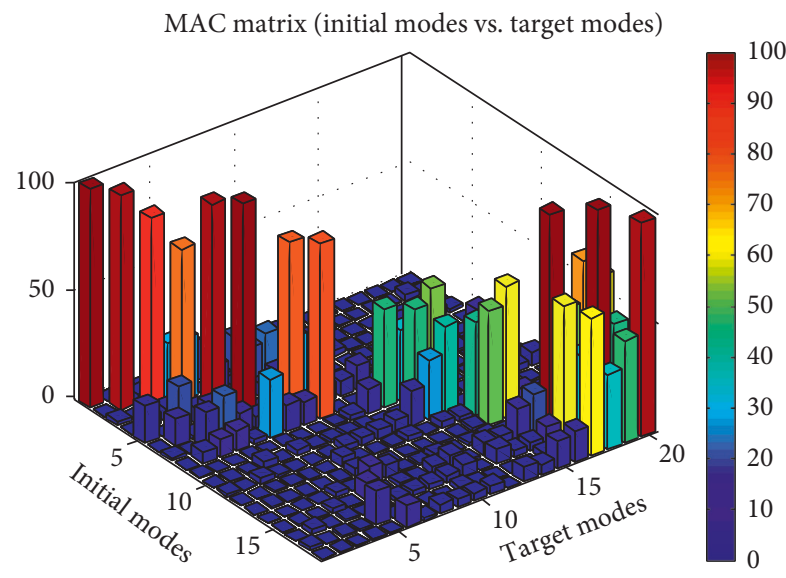

Figure 31: MAC of configuration 1 initial-target model.

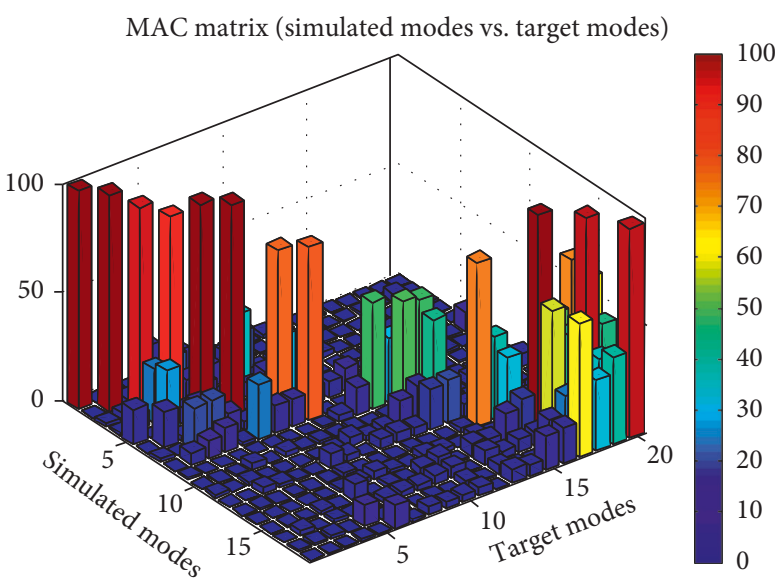

Figure 32: MAC of configuration 1 simulated-target model.

TABle 18: Fuel configurations for configuration 1 simulation.

\begin{tabular}{lccc}
\hline Mode & $\begin{array}{c}\text { Initial model } \\
\text { frequency }(\mathrm{Hz})\end{array}$ & $\begin{array}{c}\text { Target model } \\
\text { frequency }(\mathrm{Hz})\end{array}$ & \% relative error \\
\hline 1 & 3.82 & 3.82 & 0.00 \\
2 & 4.95 & 4.94 & 0.21 \\
3 & 5.41 & 5.44 & 0.56 \\
4 & 5.47 & 5.52 & 0.92 \\
5 & 6.80 & 6.72 & 1.06 \\
6 & 7.73 & 7.74 & 0.13 \\
7 & 8.88 & 8.49 & 4.68 \\
8 & 9.05 & 8.88 & 1.83 \\
9 & 9.71 & 9.14 & 6.24 \\
10 & 10.10 & 9.47 & 6.67 \\
11 & 10.41 & 10.00 & 4.18 \\
12 & 10.75 & 10.31 & 4.25 \\
13 & 11.17 & 10.89 & 2.53 \\
14 & 11.76 & 11.15 & 5.48 \\
15 & 11.99 & 11.36 & 5.56 \\
16 & 12.60 & 11.43 & 10.25 \\
17 & 12.63 & 12.03 & 5.00 \\
\hline
\end{tabular}




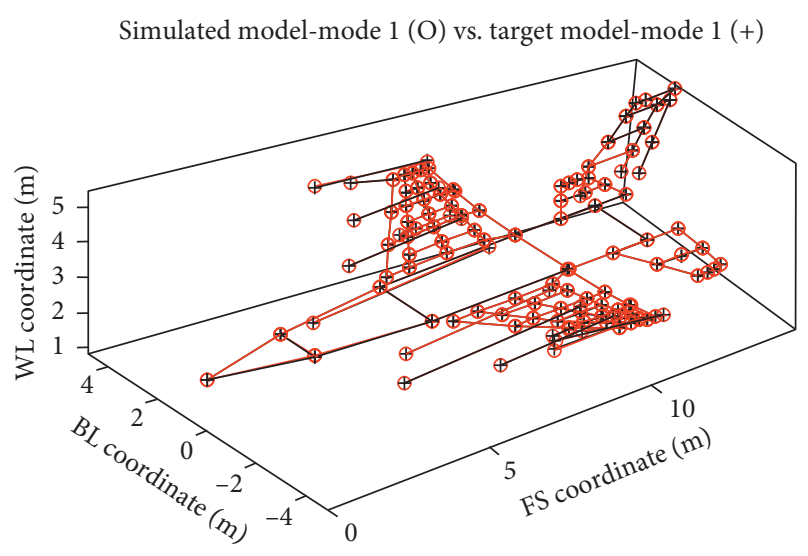

FIgURE 33: Mode shape for configuration 1 mode-1.

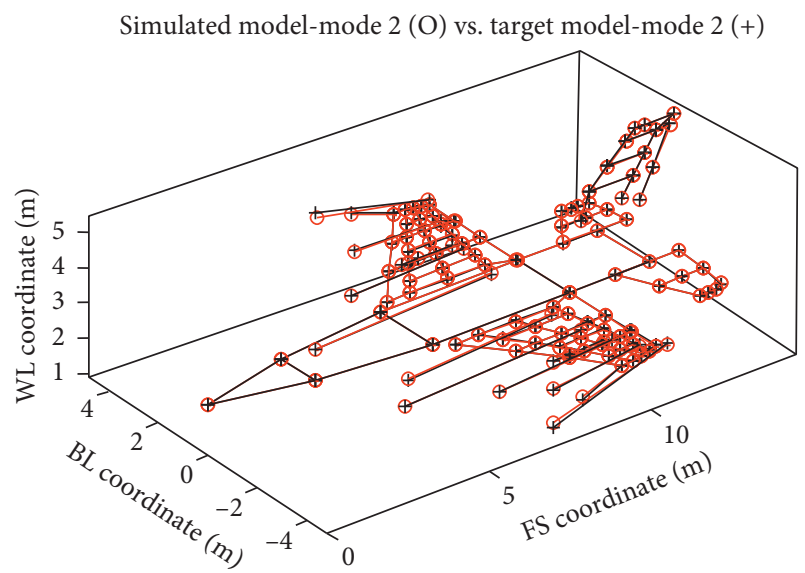

FIgUre 34: Mode shape for configuration 1 mode-2.

Comparably, some of the results of preliminary flutter analyses are so confident that the configuration can be regarded as not critical.

\section{Conclusions}

FE model of an aircraft is crucial for the planning of a GVT campaign when the flutter characteristics are in consideration. Such a detailed model may not be available for the parties who undertake the task of designing external stores or munitions to be used with the aircraft. Coordinators of such projects need to ensure the safe operation of the air platform together with the new external stores within an acceptable flight envelope when the actual FE model is not available even for the planning of GVT which is vital in the early stages of these types of projects.

In this paper, simulation of GVT characteristics for downloading and fuel configurations of F-16 aircraft is studied. FE model is built from the solid model and the technical data of aircraft which are used for the determination of geometrical, mechanical, and structural properties.

The simulations are conducted for loading and fuel configurations to determine the necessary GVT configurations and minimize the total number of tests in the GVT campaign. It is shown that GVT repetition is not necessary when the subtractive modification level is small for rigid and rigidly mounted external stores. Similarly, the effect of fuel in fuselage tanks is shown to have no effect on the structural dynamics of F-16 as expected. The dynamics of the aircraft can be fully simulated for that change by this approach. The MAC can be used as an auxiliary tool to determine the effect of the level of the subtractive modification. The response of the aircraft obtained through this analysis can be used for preliminary flutter analyses. In case of flexible stores, compliantly mounted stores, or stores near wing tips, the GVT should be performed, especially if the coupling stiffnesses are not known. Due to this reason, the GVT should be performed with maximal mass of the flexible or compliantly mounted stores. The mass decrease of the stores can be considered numerically by using this method and in the flutter analysis.

As a result of this study, modeling, updating, and verification of F-16 FE model are performed to be used in preliminary analysis and planning purposes. Prediction of GVT results for different loading and fuel configurations is made. In this aspect, the number of necessary GVT configurations for the external loads can be minimized or eliminated in the design stage up to $80 \%$. The success of the approach is shown for GBU31 configurations as $66.6 \%$ for loading and as $100 \%$ for fuel configurations if the critical frequency is determined around $8 \mathrm{~Hz}$ for first six modes from preliminary flutter analyses. The employed technique can be expanded for different aircraft and loads by using the same approach.

\section{Data Availability}

The modal and test data used to support the findings of this study have not been made available because of intellectual and industrial property rights.

\section{Conflicts of Interest}

The authors declare that there are no conflicts of interest regarding the publication of this paper.

\section{Acknowledgments}

This paper was supported by Ekinoks-AG Defence Industry Corporation.

\section{References}

[1] S. Saeed and F. Adel, "Effects of accelerometer mounting methods on quality of measured FRF's," in Proceedings of the 21st International Congress on Sound and Vibration (ICSV21), Beijing, China, July 2014.

[2] R. Bono, "Transducer mounting and test setup configurations," in Proceedings of the 26th International Modal Analysis Conference, pp. 4-7, Orlando, Florida, February 2008.

[3] M. A. Peres and R. W. Bono, "Modal testing and shaker excitation: setup considerations and guidelines," in Proceedings of the SAE 2011 Noise and Vibration Conference and Exhibition, Grand Rapids, MI, USA, May 2011. 
[4] S. A. Morton, "The role of CFD in stores certification," in Proceedings of the High Performance Computing Users Forum, Eglin AFB, FL, USA, April 2008.

[5] C. M. Denegri, "Limit cycle oscillation flight test results of a fighter with external stores," Journal of Aircraft, vol. 37, no. 5, pp. 761-769, 2000.

[6] C. Farhat, P. Geuzaine, and G. Brown, "Application of a threefield nonlinear fluid-structure formulation to the prediction of the aeroelastic parameters of an F-16 fighter," Computers \& Fluids, vol. 32, no. 1, pp. 3-29, 2003.

[7] P. Geuzaine, G. Brown, C. Harris, and C. Farhat, "Aeroelastic dynamic analysis of a full F-16 configuration for various flight conditions," AIAA Journal, vol. 41, no. 3, pp. 363-371, 2003.

[8] T. Lieu and C. Farhat, "Adaptation of aeroelastic reducedorder models and application to an F-16 configuration," AIAA Journal, vol. 45, no. 6, pp. 1244-1257, 2007.

[9] P. C. Chen and D. H. Lee, "Flight-loads effects on horizontal tail free-play-induced limit cycle oscillation," Journal of Aircraft, vol. 45, no. 2, pp. 478-485, 2008.

[10] S. Köksal, Y. Yazıcıoğlu, E. N. Yıldız, and G. O. Özgen, "Ground vibration test planning of a fighter aircraft by using a rough finite element model," in Proceedings of the ASME 2013 International Mechanical Engineering Congress and Exposition, Volume 4A: Dynamics, Vibration and Control, San Diego, California, USA, November 2013.

[11] J. P. Nöel, L. Renson, G. Kerschen, B. Peeters, S. Manzato, and J. Debille, "Nonlinear dynamic analysis of an F-16 aircraft using GVT data," in Proceedings of the International Forum on Aeroelasticity and Structural Dynamics, June 2013, Bristol, UK.

[12] Ö. Erdener, "Development of structural model of a fighter wing," M.Sc Thesis, Department of Aeronautical Engineering, Middle East Technical University, Ankara, Turkey, 2002.

[13] Ö. Erdener and Y. Yaman, "Bir uçak kanadinin yapisal modelinin geliștirilmesi," in Proceedings of the Ulusal Makina Teorisi Sempozyumu, pp. 149-160, Gazi Üniversitesi, Ankara, Turekey, September 2003.

[14] S. Köksal, "Simulation based ground vibration test planning of a fighter aircraft," Ph.D.Dissertation, Department of Mechanical Engineering, Middle East Technical University, Ankara, Turkey, 2014.

[15] FEMtools, FEMtools Theoretical Manual Version 3.1, Dynamic Design Solutions, Leuven, Belgium, 2005.

[16] D. Boyce, "Flight flutter testing, evolution of flight testing from manned vehicles to UAVs," in Proceedings of the SFTE/ SETP Flight Test Symposium, Fort Worth, TX, USA, 2013.

[17] J. T. Foughner and C. T. Besigner, "F-16 flutter model studies with external wing stores," NASA Technical Memorandum 74078, NASA Langley Research Center, Hampton, VA, USA, October 1977. 


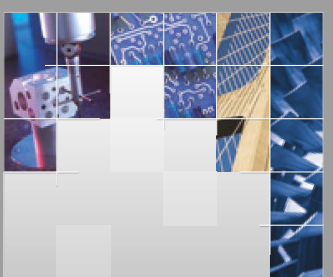

\section{Enfincering}
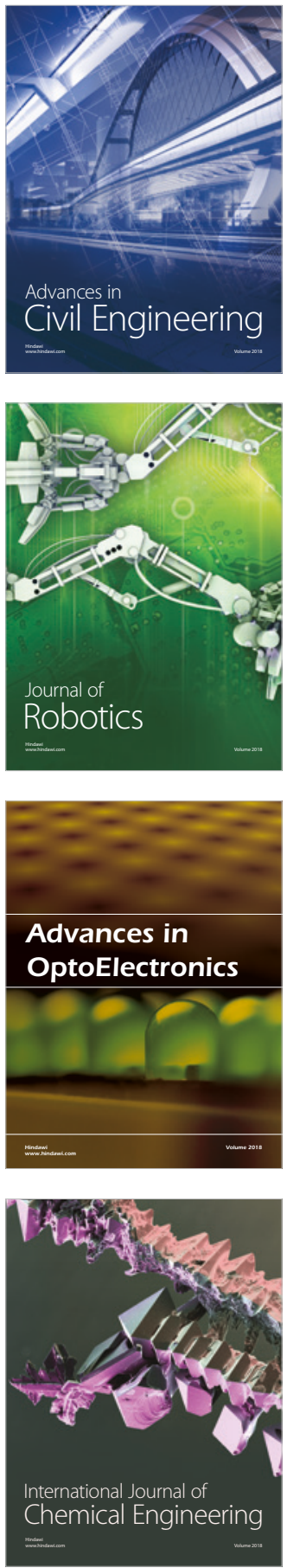

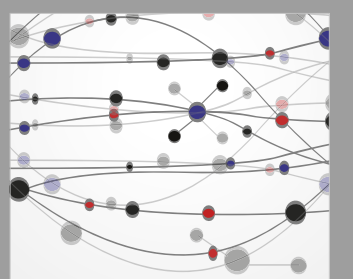

\section{Rotating \\ Machinery}

The Scientific World Journal

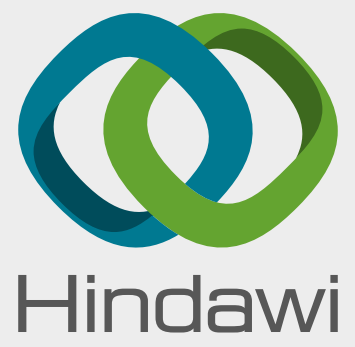

Submit your manuscripts at

www.hindawi.com
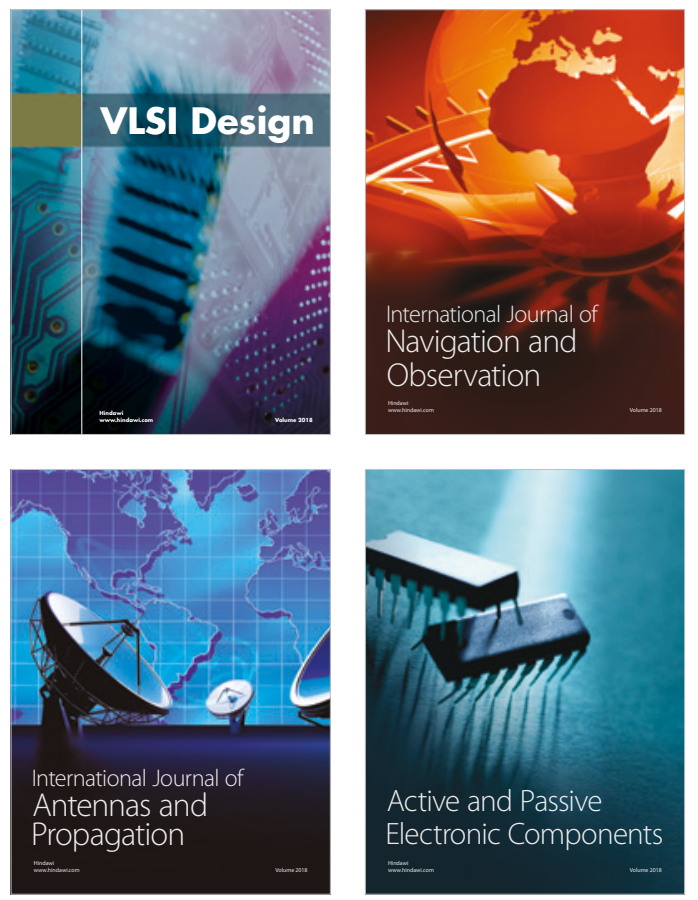
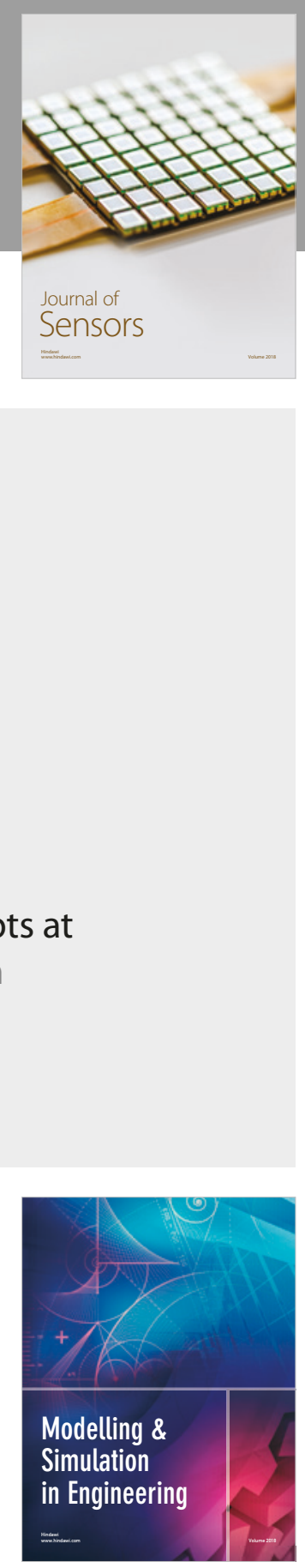

\section{Advances \\ Multimedia}
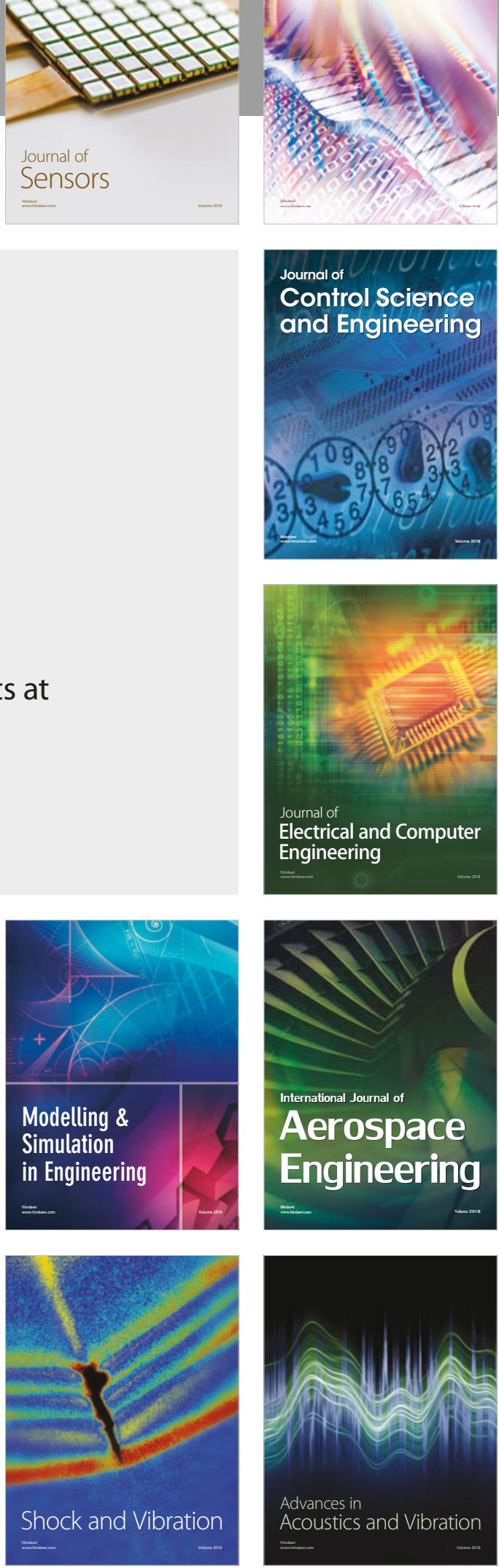